\title{
Kritischer und spekulativer Idealismus.
}

Von Dr. phil. (h., c) Georg Hagsoñ.

Für den gegenwärtigen Stand der philosophischen Arbeit in Deutschland ist nichts so bezeichnend wie das immer stärker hervortretende Verlangen nach irgend einer. Arte vōn metaphysischèr Systematik. Eine gleichsam unwiderstehliche Gewalt, die tiefer als das intellektnelle Räsonnement in das innere Leben des Menschen eingreift, treỉbt den Geist der Zeit anf die Suche nach überèmpirischer Wirklichkeit. W.as anf dem Gebiete der gebildeten und der ungebildéten Vorstellung die seltsamsten Phantastẹreien erzengt und die rückștändigssten Wahngebilde neubelebt, das bringt sich innerhab der methodischen Wissenschaft des Gedankens, in dem BewaBtsein zum Ausdrack, daB der heate dorchweg befolgten philosophischen Methode bei all ihrem formalen Scharfsinn oder gerade wegen ihres blob scharfsinnigen Formalismus ein Mangel anhafte, den es za beseitigen gelte. Nan wäre es durchaus verhängnisvoll, wenn - diese Beseitigung von einem andern Standpunkt aus versucht werden sollte als von dem letzten, den die Philosophie in ihrer bisberigen Ausbildung glücklich erreicht hat; der Hinweis anf die Blüte zuchtlosen Aberglaubens in der Gesellschaft unserer Tage muß zur dringenden Warnung dienen, daß sich das Denken, weil ihm an der gegenwärtigen Gestalt der philosophischen Wissenschaft etwas fehlt, nicht anf. längst iuberwundene Vorstellangen zarückziehe. Andererseits ist jener Rückfall in den Aberglanben ja gerade dadurch zu erklären, daß ein ursprüngliches Bedürfnis des Gemütes, dem die Zeitbildung keine legitime Nahrung zu bieten vermocht hat, sich mit Ungestüm eigenmächtige Befriedigung sucht, and man darf sicher voraussetzen, daß sobald die ernsthafte Wissenschaft in Vernunft und Freibeit ihren eigenen Mangel zn ergänzen, ihre durch lange Gewöhnong an das Weiterarbeiten in bestimmter Richtang erworbene Einseitigkeit za tuber- 
winden verstehen wird, jener Schaum der Willkürlichkeit und Abenteuerlichkeit aus dem gärenden Moste des Gemütslebens ausgeschieden werden und nur der Drang nach einem Leben im Lichte der Wahrheit übrig bleiben wird. 'Damit ist der Wissenschaft eine große Aufgabe gestellt, die aber nicht von außen ihr diktiert, sondern durch die Notwendigkeit ihres eigenen Fortschreitens in ihr selbst hervorgerufen wird und von da aus auf das Gesamtbewußtsein der Zeit einwirkt. Denn freilich ist die Wissenschaft kein vereinzeltes Faktum, das von dem großen Strome des wirklichen Lebens abgesperrt bleiben könnte; aus der Quelle der Erkenntnis, die sie sprudeln läßt, empfängt dieser Strom die wichtigsten Zuflüsse, und wenn ihre Quelle einmal spärlich oder trübe rinnt, so leidet darunter das Gedeihen der Menschheit überhaupt. Jahrzehntelang galt es bei den Pbiloșophen als ausgemacht, daß es mit der Metaphysik ein für allemal zu Ende sei;- wer in ihr noch ein berechtigtes Momènt des wissenschaftlichen Denkens sah, galt für eine Art Fossil ans gänzlich begrabener Vergangenheit. Jetzt regt sich überall dais Empfinden, daß die Wissenschaft ohne Metaphysik unvollständig sei and in ihr die Synthese finden müsse, auf die sich heute der Geist wieder richtet, nachdem er lange sich an der Analyse hat genügen lassen. Die Katastrophe d̆es Weltkrieges hat einem Żeitalter den Untergang gebracht, das 'durch die Hingebung des Geistes an die Anßenwelt charakterisiert war. Mit dem platten Materialismus und Mechanismns hat es begonnen; er war die nächste Auskanft, wo sich das Bewaßtsein von dem sogenannten Realen beherrschen ließ und sich in ihm zerstreute. Unmöglich aber konnte der Gedanke; der von Natur die Freiheit in sich trägt, auf dieser Stufe stehen bleiben; schon die Evolutionstheorie, die eben deshalb mit allgemeiner Begeisterang aufgenommen wurde, brachte in die bloße Geistlosigkeit einen - Schimmer höherer Vernünftigkeit hinein, obwobl man sie ängstlich vor jedem Anklang añ Teleologie und Ideenentwicklung zư schützen. suchte. Den Retter vor dem Versinken in den Naturalismas fand das Denken dann in Kant; für die damalige Situation war es das Añgemessene, daß er von der Seite anfgefaßt wurde, nach der er einestẹils die Möglichkeit der Naturwissenschaft und andernteils die Unmöglichkeit èiner rein verstandesmäßigen Erkenntnis des Transžendenten zạ beweisen unternommen hat. Eịn kritịscher Positivismus and Agnostizismus wurde ansgebildet, der dann durch das Geltenlassen von Gemütswerten noch einer Welt der'sub- 
jektiven Ideale neben der Welt der' exakten Erkenntnïs Raum gab; die Philosophie des „Als ob" ist der letzte konséquente Ausgang dieser Entwicklung. Indes ließ die Ż̄iespältigkeit dieses Standpunktes ein Beruhen bei dieser Auffassung der Kantischen Lehre nieht zu. Der Neukantianismus geht übệr die Scheidung von Objektivität and Sabjektivität zarück zu der Kantischen Grandanschauung, die zwischen beiden eine anlösliche Korrelation fesistellt and zwar so, daB überbaupt nur durch diẹ Erkenntnis and in der Erkenntnis etwas objektiv ist. Hierdarch verringert sich der Abstand żwischen dér Erkénntnis der empirischen BewaBtseinsinhalte und den Werten idealer Natur. Diese erscheinen als zu einer Objektivițät der Kultur gehörig, die selbstverștänd̦lịch nar durch die Vernunfttätigkeit möglich, ja nichts andëres als Vernunfttätigkeit selbst ist, jene haben keinerlei von der Erkenntnis verschiedenes Sein, sondern sind nichts als Geltung's= urteile. Das einzige Objektive, das so der Philosophie übrig bleibt, ist die Vernunfttätigkeit, dàs Errkẻnnen selbst, und die eịnzige Anfgabe der Philosophie ist die Selbstbestimmang dieses Erkennens, für das es keinen anderen Inhalt gibt als seine eigene Tätígkeit. So entsteht ein äußêrst folgerichtiger Logismus, die Anschauung eines in sich geschlossenen Ganzen intellektuëller Tätigkeit, die indes nach dem transzendentalen Prinzip des Kritizismus daranf beschränkt bleibt, die Erfahrungsmöglichkeiten za bestimmen oder einem arsprünglich Bestimmungslosen zur erkenntnismäßigen Fơrm za verhelfen. Man würde sehr unrecht tan, wenn man nicht anerkennen wollte, daß in diesem Nenkantianismus tatsächlich eine Weiterbildung des kritischen Idealismus über seine geschichtlich erste. Erscheinungsform in Kant selber vorliegt. Vielleicht darf man sogar sagen, daß hierüber hinaus es ein Weitergehen in derselben Richtung nicht mehr gibt. Die Aufgabe wäre fesselnd genug zu zeigen, wie diese extreme Zuspitzung des Transzendentalismus mit der Gestalt der Bildung zusammenpaßt, die dem jetzt zu Ende gegangenen Zeitalter sein Gepräge gegeben hat. Uns liegt eine andere Anfgabe ob. - Nicht bloB von außen verstärlzt sich dex Widersprach gegen diesen abstrakten Logismus; von ihm selbst ans bereitet sich eine Umkehr zur Versöhnung mit dem Leben der Wirklichkeit vor, von dem er sich tatsächlich allzuweit entfernt hatte. Ist es doch ungefähr der Standpankt, wie ihn Herder and Jacobi irrtümlicherweise Kant selber zugeschrieben haben, der Standpankt einer Isolierang der Philosophie, der von der 
ganzen Welt nichts übrig läbt als abstrakte Beziebungen von Denkakten, ohne doch diese Denkakte anders begreiflich machen zu können als durch die Voraussetzong eines nicht weiter za bestimmenden Anlasses für eben diese Denkakte. Aber grade dieser vollständige Ausbau der Theorie trägt das Mittel zur Heilung ihres Schadens in sich selbst. Es läBt sich der Schritt gar nicht umgehen, durch den der Wert zu einem Moment der vernünftigen Wirklichkeit, die Geltang zur Wahrheit im konkreten System des Wissens wird. Die Art, wie Artur Liebert durch die Untersuchang der Voraussetzangen der kritischen Philosophie den Weg zu einer neuen kritischen Metaphysik zu bahnen unternimmt, ist ein klarer Beweis dafür, daB im Neukantianismus eine Neuorientierung sich vollzieht.

In gewissem Sinne wiederholt sich damit die Bewegung, die. vor nunmehr fünff Vierteljahrbünderten stattgefunden hat, der Fortschritt vom kritischen zum spekulativen Idealismus, der Weg von Kant zu Hegel; und es ist gewiß kein Zufall, daß̧, nachdem der Name Hegels weit länger als ein Menșchenalter hindarch in der deutśschen Philosophie kaum noch genannt wurde, man heut überall der Bezagnahme auf ihn begegnet. Immerhin darf der große Unterschied zwischen der philosophischen Situation der Gegenwart und der Blüteżeit des deutschen Idealismus nicht übersehen werden. Damals hat, mit Kant angefangen, der durchans ein Fựhrer za neuen Zielen war, eine Reihe bahnbrecheñder Genien dem Geiste der Zeit dàs Losungswort gegeben and ihn damit gleichsam über sich selbst emporgehoben. Damals sind, wenn aúch durch Schranken des zeitgeschichtlichen Horizontes in dèr Dựchführung vielfach gehemmt, die blẹibenden Grundgedanken and beherrschenden Begriffe des Idealismus der reinen Vernnnft und der Aùtonomie des selbstbewüßten Geistes herausgearbeitet und formuliert worden. Damals machte der denkende Geist in wenigen Jahren eine-Entwickelung durch, die ein Programm für Jahrhnnderte in sich birgt. Heate muß die Philosophie mühsam darum kämpfen, die ihr gëbührende Stellung im Geistesleben der Zèit wiederzugew winnen, die sie während des verflossenen Zeitalters an die sogenannten exakten Wissenschaften verloren hatte, und noch ist kein Denker von dem Kaliber aufgetancht, daß er das BewaBtsein seiner Zeit auf die Höhe der inneren Freiheit and Klarheit emporreißen könnte, von der es lange herabgeglitten ist. Heute gilt es, die von jenen großen Lehrern uns uiberkommenen 
Prinzipien sorgfältig aüfà̀ssen, prüfen, darch: and weiterbilden and geduldig warten, ob and wann etwa die denkende Vernunft. in ihrer Selbstbetrachtong noch hinter diese Prinzipien wird zurüickgehen and eine noch tiefere Gründlegung ihrer eigenen Organisation. wird finden können. Heute sieht sich das Denken auf. dèn W.eg einer langsamen, darch die Vergangenheit beștimmten Weiterarbeit an den Aufgaben gèwiesen, die frühere schöpferische Zeiten ihm gestellt haben, and muß sich bescheiden in den Flaß einerì Entwickeluning einreihen, der das Stichwort schon vor etlichen Menschenaltern gegeben worden ist. Dafür ist dann freilich auch vom wissenschaftlichen Gesichtspankte - ein wichtiger Vorteil auf seiten der heatigen philosophischen Arbeit za buchen. Wir stèhen zeitlich. jenen Anfängèn der neuen philosophischén Betrachtungsweise jetzt fern genug, um sie unbefangen nach ihrer geschichtlichen Bedingtheit sowohl wie nach ihrem bleibenden Wahrheitsgehalt beürteilèn zn können. Wenn den Chorführern der deutschen idealistischen Philosophie in den ersten Generationen ihrer Schüler fast durchweg nar Epigonen entstanden, die von ihren Meistern die Formel entlehnten, um sie bestenfalls in geistreichem Räsonnement auf den mannigfachsten Stoff anzuwenden, so liegt darin der beste Beweis, um wie viel die ursprünglichen Gedankenschöpfungen jener Großen über die Schranken ihrer Zeit hinwegragten. Nachdem sich inzwischen die Zeiten zweimal gänzlich gewandelt haben, nachdem die erste, unmittelbare Gestalt jener idealistischen Philosophie von dem lebendigen Geiste verlassen worden ist und als ein Denkmal der Vergangenheit dasteht, dem unser Nachdenken erst wieder Leben einflößen $m a B$, sind wir auch eigentlich erst in den Stand gesetzt, uns mit freiem Verständnis an diese Philosophie heranzamachen, in sie einzagehen, ihre letzten Motive and den ihren geschichtlichen Ablauf beherrschenden Begriff za erfassen. Wenn also jetzt der Weg vom kritischen zum spekulativen Idealismus wieder sollte zurückgelegt werden, so wäre das eine Wiederholung gleichsam in zweiter Potenz, eine Wiederholung mit dem Bewaßtsein, dak, and mit der Einsicht, waram und wieweit es eine Wiederholng ist und sein muB.

Die Aufgabe, diese beiden Standpunkte zu vergleichen, läßBt sich demnach nicht dadurch erschöpfend lösen, daß man nar den Hergang ihres ersten geschichtlichen Auftretens betrachtét and an der Form Kritik übt, in der sie damals gegeneinander sich erhoben und abgegrenzt haben. Es kommt daraaf an, den prin- 
zipiellen Unterschied ans licht zu heben, der sie gleichzeitig trennt and eint and der, aller geschichtlichen Abwandlangen ungeachtet, unverändert derselbe bleibt. Daß dafür der Rüickgang auf die gleichsam klassische Zeit ihrer Ausbildung nerläßlich ist, versteht sich von selbst; ohnehin aber kann man heute sich za jener Vergangenheit gar nicht anders hinwenden als ausgerüstet mit dem Begriffsvorrate, in dem man durch die gegenwärtigen philosophischen Methoden heimisch gemacht worden ist. Der hier sich zeigenden doppelten Gefahr, in die früheren Theoreme moderne Beziehungen hineinzuinterpretieren oder das heatige Denken an die Schemata vergangener Gedankenrichtungen zu binden, entgeht nar der, dem es gelingt; sich denkend über die zeitlichen Bedingtheiten sowohl von damals wie von jetzt za erheben und die Seele, den lebendigen Begriff za erfassen, der sich in den verwandten Denkweisen verschiedener Zeiten .verschiedenartig verkörpert. Naturgemäß wird auch da noch sich ein. Unterschied, wenn nicht in dem endlichen Ergebnisse selbst, aber doch in dem Ausgangspunkte, von dem man sich ihm nähert, and in dem Wege bemerklich machen, auf dem man es erreicht, je nachdem man nämlich selber gewöhnt gewesen ist, in den Gedankenreihen des einen oder des andern Standpunktes sich zu bewegen. In dieser Hinsicht hat es heute der Denker, der aus dem Lager des kritischen Idealismus stammt, leichter, Gehör za finden, als wer von je an die Gesichtspankte des spekulativen Idealismas sich zu eigen gemacht hat. Jenem werden zur Zeit die meisten Hörer und Leser mit willigem Vertráuen entgegenkommen, weil sie mit ihm den gleichen Gedankenansatz haben, während ihnen die Anschaungsweise, die der spekulative Idealist bei dem besten Willen, auf die Denkart der andern Seite einzugehen, doch niemals ganz verleugnen kăinn, von vornherein befremdlich und sogar abstoßend erscheinen wird. Bedenkt man vollends, daß, sobald auf die tiefsten Fundamentte, auf die entscheidenden Differenzen zwischen beiden Standpankten zarücḱgegángen .w̄ird, Gegensätze hervortreten, die nicht von heut and gestern stammen, sondern die Probleme des philosophischen Denkeñs von jeher gewesen sind, so tritt dem Versuch einer Verständigang noch eine weitere Schwierigkeit in den Weg. Es scheint nämlich, daß über diese letzten Unterschiede nichts Neues mehr gesagt werden könne; sie sind längst nach allen Seiten erörtert worden, und von beiden Standpunkten aus hat man ihren Sinn, ihr Verhältnis za einạder, ihre geschichtlichen und gedank- 
lichen Verbindungen und Entgegensetzungen in aller Šrgfalt auseinandergelegt. Das gilt ebenso von der Darstellung des Weges von Kant zu Hegel, wie von der prinzipiellen Darstellung d̈er Transzendentalphilosopbie und des absoluten İdealismus. So lautet - denn, wenn aus dem einen Lager wieder einmal eine solche 'Därstellung hervorgeht, die Antwort aus dem andern; daß sie keine neuen Gesichtspunkte bringe, und die Replik darauf beschwert sich, daß die Gegenseite immer wieder ihre längst widerlegten̆ Argumente vortrage. Mit diesem gegenseitigen Vorwurf aber, $\mathrm{da} \beta$ der andere beständig zurück nur komme auf sein erstes Wort, wenn man Vernunft gesprochen stundenlang, ist natüilich nichts ausgerichtet. Der Weg zür Verständigang zwischen beiden Lagern kann nur in dem einen Umstande gefunden werden, daß nicht von der Gegenseite her, sondern durch immanenten Fortschritt innerhalb der eigenen Denkweise der Anstoß gegeben wird, den eigenen Standpunkt zu revidieren und sieh dadurch dem andern za nähern: Da gegenwärtig im Lager des kritischen Idealismus ein solcher Revisionsprozeb vor sich geht, so wird dem Vertreter des speku= lativen Idealismus äm sö mehr die Bescheidenheit geziemen, nicht durch rechthaberisches Auftrumpfen diese Bewegung zu stören, sondern sich anf. den Versuch zu beschränken, wie er Mißverständnisse, die eine Annäherung erschweren, aus dẹm Wege räumen und den Ausgleich der Gegensätze durch ihre möglichst klare Formulierang von seiner Auffassungswèise aus fördern könne. 、

Die folgenden Betrachtungen möchten in diesem Sinne verstanden werden. Sie sind veranlaßt worden durch das Erscheinen des dritten Bandes von Ernst Cassirers ausgezeichnetem Werke über die Geschichte des Erkenntnisproblems ${ }^{1}$ ). Eine Besprechung des Buches, die seinem reichen Inhalte auch nur annähernd gerecht, werden woilte, würde einen Umfang annehmen müssen, der sie selbst $z \mathfrak{a}$ einem Buch aufschwellen würde. Mit einer bloßen Lobpreisung der Sorgfalt und Klarheit, des liebevollen Eingehens and nachfühlenden Verständnisses, womit der Verfasser die bante Reike der von ihm betrachteten Systematiker dem beutigen Denken nahebringt, würde ihm nicht gedient sein. Den besten Beweis für den Wert seines Buches wird die Tatsache

1) Ernst Cassirer, Das Erkenntnisproblem in der Philosophie und Wissenschaft nnserer Zeit. 3. Bd. Die nachkantischen Systeme. Berlin 1920, Bruno Cassirer. 
liefern, daß es Gelegenheit zo fruchtbarer Disknssion bietet; und wenn wir zam Thema dieser Diskussion die Frage nach dem Verhältnis zwischen kritischem und spekulativem Idealismus wählen, so glauben wir damit das Problem aufgegriffen za haben, das ebensowohl in dem Mittelpunkte des Cassirerschen Buches wie der wissenschaftlichen Bemühungen seines Verfassers überhanpt steht. Denn für ibn vor allem ist das Bestreben bezeichnend, unter grundsätzlichem Verharren àf dem Standpankt der kritischen Philosophie den Ertrag der Geisteskultar festzuhalten und weiter auszubauen, den wir den großen Vertretern des spekulativen Idealismus verdanken. Es wäre zu viel gesagt, wollte man seine Denkweise nach bekanntem Muster so bezeichnen: mit dem Kopf ein Kantianer, mit dem Herzen ein Fichteaner, wenn nicht gar ein Hegelianer; aber $\mathrm{daB}$ sein Herz Goethe gehört, und daB in Goetbe nicht bloß Leibniz mit Spinoza, sondern auch Kant mit Schelling und Hegel in ganz wunderbarer Integration verschmolzen erseheinen, das wird man wohl behaupten und von daher das Interesse Cassirers für den spekulativen Idealismus herleiten dürfen. Da er in seinem Buche die historische Darstellang mit prinzipieller Auseinandersetzung regelmäßig verbindet und sogar am Schlusse seiner Schilderang des Hegelschen Systems einen besondern Abschnitt bringt, der von „dem kritischen und dem absoluten Idealismus" handelt, so ermöglicht das Eingehen auf dies Buch die Erörterung des Themas in seiner ganzen Bedeutung. Jedoch wird die Rücksicht auf den Raum uns dazu nötigen, aus der Fülle der einzelnen Punkte, die der Erörterung wert wären, nur einige herauszugreifen, die uns besonders dazu geeignet scheinen, Kopf und Herz in Rücksicht auf den spekulativẹn Idealismus za versöhnen.

- Es haridelt șich für uns um żwei Formen des Idealismus, d. ha. um zwei eng verwandte Denkweisen, deren Verschiedenheit eben daram so scharf hervortritt, weil sie sich so außerordentlich nahe stehen. Das Gemeinsame der beiden aber ist diejenige Stellung des wissenséhaftlichen Denkens, die der tatsächlichen Stellung des Menschen in seiner Welt am genauesten entspricht. Der Mensch ist, weil er denkendes Wesen ist, an sich oder von Natur Idealist, auch wenn er es șelbst nicht weiß: Es gibt für ihn ohne die Vermittelung seinies Innern keinerlei Wirklichkeit; daß er sich von dem allen unterscheidet, dessen er sich bewaßt ist, auch von sich selber, and dieses alles immer in Beżiehung auf sich sieht und 
empfindet, macht-ideell beständig die ganze Welt von ihm abhä̀ngig, wie stark er auch reell von ihr abzahängen "scheint. Infolgedessen ist insbesondere das theoretische Verhalten des Menschen als solches idealístisch, und alle Philosophie, sie màg. eine Richtang haben, welche sie wolle, ist deshalb, weil sie das. scheinbar selbständige Objekt - mit dem Verstande sich unterwirft and denkend erfaBt, Idealismus schlechthin. Auch der philosophische Materialismas kommt davon nicht los, Idealismus zu sein; er gibt eine gedankliche K' ${ }^{\prime}$; struktion der Wirklichkeit; and wenn er meint, die Wirklichkeit nur, anfzanehmen; wie sie an sich ist, so fügt er ihr eben doch berêits därch dies Aufnehmën eine Beziehang za dem dènkenden Subjekt hinzu und übersetzt sie aus einer Sphäre des bloßen Daseins in die Sphäre des Gedachtwerdens. Dem Denken koninte, sobald es anfing, sịch auf sich zu besinnen, dies Verhältnis nicht lange verborgen bleiben; innerhalb der Philosophie bat sich von früh an àls diejenige, die schließlich den entscheidenden Antrieb zú der Fortbildung auch aller andern neben ihr bestehenden Richtungen in sich trägt, der philosoplaische Idealismus entwiekelt. Gânz im allgemeinen ist er als die Anschanung zu bezeichnen, die als das Wirkliche, das.Wahre, das Geltende, das Wertbetonte - man mag die verschiedenen Ausdrücke zunächst freigeben - dasjenige erkennt, was der sinnlichen Wahrnehmung; der Erfahrung einer Außenwelt nnzugänglich ist, Bestimmnngen des menschlichen Inneren, Inhalte des Denkens, der Tätigkeit des Sabjekts, die als bleibendẻ Formeñ, erhaltende Gründe, leitende Zwecke an dem Wechsel der raumzeitlichen Erscheinung nicht teilnehmen. Es ist das unsterbliche Verdienst der Antike, diese Inhalte in ihrer nächșten einfachen Bestimmtheit ans Licht gestellt and formaliert $z \mathrm{a}$ haben; sie hat den objektiven Idealismas geschaffen, dessen Hauptproblem die Frage bildet: was ist das Wahre?. Es liegt aber auf der Hand, daB davon die andere Frage nicht zu trennen ist: welches ist der Weg zu dem Wahren? Wenn Plato in eingehenden Untersuchungen die Wahrnehmung, die Vorstellang, die richtige Meinung nicht als wissenschaftlich zareichende Mittel zur Wahrheitserkenntnis gelten läBt nnd das begriffliche Denken als den einzigen Weg zum wahren Wissen erweist, so treibt er bereits Exkenntniskritik; diese also ist nicht das Privileg des kritischen Idealismus. Wenn Plato ferner von den Philosophen erklärt, daB sie sich im Sterben üben and ans der Welt der Erscheinungen abscheiden, um das Wahre za erfassen, 
so vertritt er bereits einen Standpunkt, der das Erkennen transzendental bestimmt als von Bedingangen ausgehend, die in ihm selber liegen und alle Erfahrung erst möglich machen; anch der transzendentale Gesichtspunkt ist nicht erst im kritischen Idealismus anfgetaucht. Und wenn dann Aristoteles den Gegenstand der äaßeren Erfahrang analysiert und als die beiden Momente, die ihn konstituieren, die Materie und die Form bezeichnet, die die Idee dieser Materie ist, so hat er damit die Erfahrang schon als das geistige Setzen einer Beziehung zwischen zwei für sich allein nirgend gegebenen oder möglichen Faktoren bestimmt. Es ist demnach za, sagen, dab in dem objektiven Idealismus der kritische bereits als ein noch nicht zar Selbständigkeit herausgebildetes Moment vorhanden ist.

Erst im Gefolge der Reformation tritt eine grundlegende Weiterbildung des Idealismus dadurch ein, daß sich das denkende Ich als das Prinzip der Selbstgewißheit und den Zentralpankt des gesamten Bewußtseinsinhaltes erfaßt. Das Cartesische cogito, ergo sum erweckt zuerst einen Ontologismus, der die antike Metaphysik in eine Weltanschanang des aufgeklärten und vernünftigen Bewaßțeins übersetzt, und wird dann zar Grundlage eines subjektiven Idealiṣmus, dem nichts als die Tatsạchè dẹ Bewaßtseins selbst gewiß ist. Die Welt ist die Welt unserer Wahrnehmungen; außerhalb unserer Wahrnehmungen von einer matẹriellen Welt zu reden hat keinen Sinn: die "Dinge ${ }^{\text {" existieren }}$ nur im wahrnehmenden Geiste. Mit diesem sübjektiven Idealismus könnte der absolute zusammenzufallen'scheinen, wenn nicht der Ausgangspunkt, die Wahrnehmung, selbst nicht das reine, durch sich selbst bestimmte, sondern vielmehr das zufällige, natürlich bestimmte Subjekt voraunssetzte; man kann ja um desw̧illen Berkeley auch unter die Sensualisten rechnen. Die Analyse der Erfahrung führt nun aber za der Ërkenntnis, dab die Welt unserer Wahrnehmungen gar nicht durch die einzelnen Wahrnehmungen ihre Gestalt erhält, sondern durch die Formen, in deñen der denkende Geist diese Wahrnehmungen miteinander verknüpft: Hier ist der Wendepunkt des philosophisçhen Denkens der neuen Zeit erreicht. Denn von dieser Erkenntnis, aus fälltt einerșeits jede Möglichkeit hin, eine Realität 'der Außenwelt gesondert von der Aktivität des Bewußtseins festzuhalten, und eröffnet sich andererseits der Wèg, Aüßènwelt and Innenwelt, - Natur and Freiheit in den vernünftigen Zusàmmenhang einer einheitlichen geistigen 
Produktion hineinzustellen. Den Nachweis des ersten Satzes hat Hame geliefert: die Kategorien gehören unserm Verstandë, nicht den Dingen an; also ist die Welt, wie wir sie uns vorstellen, eine durch unsere Verstandesformen erzeugte fable convenue. Man kann in den Dingen, deren Eindrücke auf uns die Wahrnehmungẹn hervorrafen, keine Kausalität nachweisen, denn die Kausalität ist unsere Vorstellungsart; deshalb ist es gänzlich ungew wị, ob die Welt unserer Wahrnehmungen irgend etwas mit der Welt. der Dinge gemein hat. Bei dieser Schlußfolgerang widerfährt freilich Hume das Mißgeschick, daß er die Kausalität, derèn objektive Gültigkeit er bestreitet, gerade an der entseheidenden Stellẹ selbst maß gelten lassen; er müßbte ganż wie Berkely. im subjektiven Idealismus stehen bleiben, wenn er nicht die Perzeptionen und Sensationen als v er urs a cht durch änßere Einwirkungen auffaßte. So ruht sein Empirismus anf einem offenkundigen Selbstwiderspruch; es wird hier unausweichlich klar, daß eine Zweiteilung in eine Welt der Dinge und in eine Welt des Bewabtseins in dem Angenblick unmöglich geworden ist, wo die kategoriale Form jeder Erkenntnis, auch der empirischen außer Zweifel steht.

Die Philosophie ist damit auf dem Pnnkte angekommen, sich ihres eigentlichen Charakters bewaßt żn werden; haben wir oben bemerkt, daß sie ihrem Wesen nach Idealismus sei, so wird nun dies ihr Wesen auch zu ihrer Tat. Hierin liegt die epochemachende Bedentung der Kantischen Philosophie; Kant erhebt die Idee der Philosophie zar lebendigen Substanz seines Sÿstems and macht mit der Erkenntnis ernst, daß das vernünftige Subjekt, das denkende Ich der Schöpfer der Wirklichkeit, daß bereits die Welt der äuBeren Erfahrung eine Welt des Geistes and dab die Freiheit die fandamentale Bestimmung der Vernanft ist. Das ist, könnte man sagen, absolnter Idealismus; wenn zwischen diesem and dem Kritizismas dennoch eine scharfe Trennungslinie gezogen wird, so liegt der Grund dafür jedenfalls nicht in einer verschiedenen Stellung dieser beiden Richtungen zu den Metboden des vorkritischen Denkens. Es ist einfach ein sachlicher Irrtam, wenn man dem absolnten Idealismus vorwerfen möchte, er sei in den Dogmatismus der ontologischen Metaphysik zurückgefallen. Daß während seiner Aasbildang sein Prinzip nicht gleich in allen Beziehnngen rein durchgeführt worden ist, besagt so wenig gegen das Prinzip, wie die mannigfachen Residuen von Psychologismus and Empirismus bei Kant etwas gegen dessen kopernikanische Tat 
besagen. Der absolute Idealismus ist mit dem kritischen völlig eins, soweit es den Unterschied von den übrigen philosophischen Standpankten gilt, die dem Leben des Geistes irgend eine dingliche, geistfremde Wirklichkeit vorausschicken und es davon abhängig sein lassen. $\mathrm{Er}$ ist selbst mit Bewaßtsein kritisch und bemängelt an dem Kritizismus nur, daß dieser nicht zam Bewaßtsein davon kommt, daB an sich auch er bereits absoluter Idealismus ist. Was also die beiden Standpunkte trennt, ist eine immanente Verschiedenheit, eine. Unäbnlichkeit von Geschwisturn. Es handelt sich allein um die Beantwortung der Frage: wie weit kann die Vernunft durch ibr Denken in der Errkenntnis ihrer selbst kommen? Während hier der kritische Idealismus eine nie ganz aufzuhebende Schranke statuiert and die Vernanft an eine ibr unentbehrliche und von ihr nicht überwindbare Gegebenheit, ein mit ihr zugleich gesetztes Irrationales and eine ihr naturnotwendig anhaftende Mehrheit von Anlagen und Vermögen bindet, will der abselute Idealismus den Gedanken der Spontaneität der Vernunft bis za Ende deñken und behauptet das Recht einer Vernụnftphilosophie, für die alle scheinbare Gegebenheit und alles scheinbar Irrationale als freie Setzung des Geistes erkannt wird, der sich selbst und alles andere produziert. Die Kritik der Vernanft, die dieser absolute Idealismas übt, bleibt also nicht bei dem Feststellen von Schranken stehen, sondern wendet sich auch kritisch diesem Feststellen zu und findet den Grund dafür in der Selbsttätigkeit des Geistes, der, indem er sich selber Schṛanken zieht, über diese Schranken bereits hinaus und ihr eigner Schöpfer ist. Weil das Denken so das Ganze aller Erkenntnisse nnd Bewaßtseinsinhalte in einem aus seiner eigenen. Vernünftigkeit and Freiheịt erz̃eugten vernünftigen Zusammenhange schaut; der durch sich selbst klar und in dem sich die Vernunft selbst durchsichtig ist, trägt diese Form des philosophischen Idealismus den Namen des spekulativen Idealismus. Dieser behauptet von sich, daß er die rechtmäßige Dürchführung dẹs von Kant aufgedeckten Prinzips dars̄telle, dah also der Weg rom kritischen zam spekalativen Idealismus der notwendige Weg des vernünftigen Denkens sei. Der Kritizismuis hinwiederum gibt heuté, im Rückblick auf die geschichtliche Entwickelúng, ohne weiteres zu, daß dieser Weg freilich einmal gemacht werden mußte und auch in seiner Weise die Philosophie mannigfach gefördert hat, sieht aber doch in ihm ein Abenteuer des Gedankens, eine Hÿbris der mensçhlichen Ver- 
nunft, die deshallb seinerzeit mit kläglichem Zusammenbrach gestraft worden and za stets' erneatem Scheitern auf ewig verđaimmt sei. Lange schien dies Urteil das endgültige za sëin die Gegenwart zeigt, da $\bar{B}$ eine Nachprüfung unerläßlich ist. Sehen wir za, welches Material Cạssirer dafir beibringt.

Wir greifen zunächst eine Reihe ${ }_{4}$ von Bemerkungen hèraus, in denen Cassirer sehr nachdrücklich den ursprünglichen Kàntianismus als noch unfertig charakterisiert. Ganz im Sinne echter geschichtlicher Auffassung sagt er (S. 2): „Der Zerfáll des kritischen Sy̆stems in seine einzelnen verschiedenartigen Elemente bedeatet zugleich die Vorbedingang and den Anfang eines nẹen Verständnisses seines begrifflichen Aufbaus" und bezeichnet als die Gruppe von Begriffen, in denen das Problem des kritischen Systems sich ausdrückt and die deshalb der weiteren Bearbeitung därch die nachkantischen Systeme anheimfallen mußten, die Begriffe des Dinges an sich, der synthetischen Einhê̈it, des Gegensatzes vion Form and Materie und des Verhältnísses von Allgemeinem and Besonderem innerhalb der Erkenntnis. In diesen Begriffen und Problemen liege ein intellektuelles Bezugsystem vor, auf das alle charak: teristischen and entscheidenden Einżelbestimmungen in den Lehren der maßgebenden Denker von Reinhold bis Hegel hinweisen (S. 3). Wenn sich wohl za diesen Begriffen and Problemen noch manche nicht minder fandamentale wïrden hinzufügen lassen, dje darch die kantische Lehre noch nicht zur Klarheit gebracht worden waren, so darf man Cassirer ohne weiteres beistimmen, dab die von ihm genannten in der Tat den kritisehen Punkt innerhalb des Kritizismus betreffen; sie können in dem einen Problem eines ursprünglichen and durchgängigen Dualismus zusammengefaßt werden. Freilich erhebt sich dann anch sofort die Frage, worauf eigentlich Kants Absicht gegangen sei; auf die Überwindung dieses Dualismus, den er aus der zeitgenössischen Philosophie übernommen hatte, durch seine Einordnang unter die Einheit des antonomen denkenden Subjekts, oder anf die Neubegründung des Dualismus, dẹn er der dogmatischen Metaphysik entgegenstellte, durch das Festhalten an dem Phänomen der sinnlichen Erfahrung. Dass er zur Abwehr des Dogmatismus sich immer wieder dem fruchtbaren Bathos der Erfahrung zugeneigt hat, ist gewiB unbestritten. Aber ebensowenig läBt sich verkennen, $\mathrm{daB}$ er über die ursprüngliche Entgegensetzung der in der Erfahrung vorgefundenen Elemente hinaus einer Synthese zugestrebt hat, die mehr bedentete als die bloB 
formal logische Korrelation dieser Elemente im DenkprozeB. Er ist zu dieser Synthese durch eine Erweiterung des Erfahrungsbegriffs gelangt, den er aus der Sphäre der sinnlichen auf die der sittlichen Erfahrung ausdehnte, und man sollte endlich aufhören das wegzulengnen, was er selbst offen erklärt hat, dab ihm die kritische Analyse der Bedingangen einer möglichen sinnlichen Erfahrung ausdrücklich dazu hat dienen sollen, die Unbedingtheit der praktischen Vernunft, die Selbstgewißheit des moralischen Willens festzustellen und eine Wirklichkeit der inneren Erfahrung zu erweisen, in die sich die Welt der äußeren Erfahrung einzu: gliedern hat. Die praktische Freiheit wird durch Erfahrung als eine Kausalität der Vernụnft in Bestimmung des Willens erkannt (Kr. d. r. V. 2. Anfl., S. 81); dem bestirnten Himmel über mir tritt das moralische Gesetz in mir als Erfahrungstatsàche zur Seite. Diese Tatsache aber ermöglicht nun vermittelst des Begriffs der Autonomie die konkrete Synthese von Phänomenen uñd Noumenen.

Die Téndenz Kants aúf den einheitlichen Aufbau der Êrkenntnis aus ihrer eigenen Gesetzlichkeit bezeichnet Cassirer als den Kèrn der Vernunftkritik. Rückhaltlos gibt er zu, daß die ersten Abschnitte der Kritik der reinen Vernunft den Sachverhalt, den Kant aufžudecken beabsichtigt, $n$ ñoch nirgends in ṽoller Klarheit hervortreten lassen" (S. 7). Auch die Darstellung in den Prolegomena gibt er einfach preis (S. 9). Er betont, daß sich in Kants Stil „der Kampf zwischen der neuen logischen Begriffsansicht and der empirischen Dingansicht fortsetzt und darin seinen deatlichșten Ausdruck erhälț" (S., 5). Den Aușdraçk "Anlagèn" für die Voraussetzungen der Form aller Erkenntnis, den Ausdrack "Affektion durch die Dinge an sich" für die Voraussetzungen zu materialer Begriffsbestimmung nennt er Symbole für das Problem des Kritizismus, niçt Lösungen. Er meint, daß auf dem Boden der transzendentalen Ästhetik „das Ding einstweilen nur als ein unbegriffeñer Rest erscheinẹ muß, der für das Wissen zurückbleibt“. Das Gemüt und die Dinge an sich treten hier als absolute, für sich bestehende Potenzen auf; $n$ die originale und tiefere Fräge, wie sich.die Welt der Erfahrung als ein einheitliches Ganzes des Sinnes and der Erkenntnis konstituiert", bleibt -noch verdèckt (S. 7). Erst mit der transzendentalen Logik tritt der kantische Gedanke klar zutage; indem die Bestimmung der Gegenständlíchkeit schlechthin kategorialen Charakter erhält, scheint es 
jetzt freilich, als habe die Vernatriftkritik hier in dem Ziel, za, dem sie jetzt gelangt, ihren eigenen Anfang zuníichte gemacht" (S. 8). Das heiBt, es ist in der Tatas dem Dualismus von Sein und Denken ein monistischer Idealismus der logischen Beziehungssysteme von Gedankenbestimmungen geworden; was ihn von dem Gipfelpunkte des absoluten Idealismus, dem ${ }_{n}$ Sichselbsterkennen im absoluten Anderssein " noch trennt, ist nar der. Umstand, dạß die Beziehwing in der Form der. Reflexion ursprünglich entgegengesetzter Momente anfgefaßt und also das Denken mit einer von ihm nicht auflösbaren Gegebenheit belastet wird.

$\mathrm{DaB}$ der Kantianismus zu solcher idealistischen Einheitslehre hintreibt, erläutert Cassirer ferner sehr interesssant an der kri; tischen Auffassung des àposteriörischen Urteils. Err weist nach, daß̣, da die Kategorien die notwendige Bedinğang aller möglichen Wabrnehmungen sind, đie empirisehè Tatsaehe selbst in dem, was gerade ihren eigentümlichen Sachcharakter ausmacht, durch niehts $\hat{s}_{t}$ anderes konstituiert wird als durch jenes reine Geltungsmoment, das im Gedanken dẹr apriorischen Synthesis festgehalien ist (S. 10). Aus dem besondern Dialekte der Sehule in die geläufigeren Ausdrücke des überlieferten philosophischen Sprachgebrauches übersetzt, besagen' diese Worte, daß die vollständige Form der ' $\mathrm{Er}$ kenntnis nicht im Urteil, sondern im Schlusse zu finden ist und daß jedem besondern Erfahrungsarteil immer bereits ein Vernunftschluß zagrunde liegt, der überhaupt eine Erkenntnis erst möglich macht. Es zeigt sich hier der eínheitliche Erkenntnisgrand, der Boden einer synthetischen Vernunfttätigkeit, die, wie Cassirer sagt, zwischen den gegensätzlichen Bedeutangsmomenten, dem Notwendigen und dem Zufälligen, dem Allgemeinen ond dem Einzẹlnen, dem Gesetze und der Tatsache, die wesentliche Verknüpfung bewirkt, ohne die Gegensätze, die isoliert nicht bestehen können, aufzalösen (S. 10). So entsteht für die kritische Betrachtung der Grundgegensätze ${ }_{n}$ stets die Doppelanfgabe: eine unlösliche Korrelation $\mathrm{zwischen}$ Bestimmungen zu schaffen, ohne sie ihrém Begriffe nach in einander aufgehen za lassen" (S. 11). Merkwürdigerweise hat Cassirer nicht gesehen, daß er hiermit das Wesen der vielberufenen dialektischen Methode genau beschrieben hat. Die kritische Methode ist tatsächlich ihrem Wesen nach dialektische Methode; was sie von deren reiner Ausbildung and bewaßter Übung noch trennt, .ist nar der Emstand, daB sie 
vorstellungsmäßig die reinen Gedankenbestimmungen selbst wieder in der Weise einander repellierender Einzeldinge auffabt and den Sinn der Identität des Unterschiedenen oder den Begriff der übergreifenden geistigen Einheit nicht erreicht. Ihre Dialektik bleibt deshalb in Reflexionsbestimmungen stecken und kommt nicht zu einer lebendigen Systematik des Allgemeinen und Besonderen.

Diesen Mangel hat Cassirer treffend hervorgehoben. Der Schematismus der reinen Verstandesbegriffe, durch den die Kritik der reinen Vernunft das Verhältnis des Allgemeinen and des Besonderen neu za bestimmen versucht, mag zwar, wie er sagt, ein Nebeneinanderwirken von Sinnlichkeit and Verstand allenfalls verständlich machen, ist aber nicht imstande, die innere wesentliche Heterogenität $z w i s c h e n$ beiden za vêrsöhnen, sondern verschärft sie vielmehr (S. 11). Die hier gestellte Aufgabe, der Gedanke, auf den die Lehre vom Schemàtismus hinzielt, hat die entscheidende Ergänzang und Erfüllung erst in der Kritik der Urteilskraft ge= funden. Sie fragt, wie Cassirer meint, nach dem Grund und dem transzendentalen Rechte der Besonderung der Verstandesgesetze selbst (S. 12); das bedeutet nichts anderes, als daB sie an die Aufgab@ herantritt, die den -Begriff der Vernunftkritik erst vollendet, nämlich den kritischen Standpunkt selbst zu kritisieren und aus der Analyse der Erfahrung zu dem System des Erfahrbaren vor= zudringen. Die Angemesssenheit der Natur für unsern Verstand setzt als Bedingang für alle empirische Forschang den Grandsatz einer bis ins einzelnste durchgehenden' Zweckmäßigkeit, eines vernünftigen, gesetzlichén Żnsammenhanges der ganzen Erfahrnngswelt voraũs, in dem sich das auf einer Stufe als zufällig Er: scheinende auf einer höheren Stufe als vernünftig bestimmt, sich als. Bestandteil eines Sýstems verständlich machen läßt. Hier ist eine Einheit der Idee erreicht, und dieser Fortschritt ist zustandegekommen, als „Kant das konkrete Prinzip der Einzelforschang selbst auszusprechen suchte and andererseits im Problem der organischen Zweckformen einen neuen und sicheren Begriff der Natur gewann "' (S. 14f.). Die Eirfahrung wird jetzt nicht mehr lediglich als mathematische Naturwissenschaft anfgefaht, und mit dem Gedanken eines ,intellectus archetypus, eines göttlichen Verstandes, der als schöpferisches, zwecktätiges Prinzip den Weltzusammenhang in seinen verschiedenen Ordnungen einheitlich gestaltet, lebt nicht nar der Leibnizisehe Begriff der Harmonie wieder auf; sondern öffnet sich aufs neue eine Erkenntnisweise, die; als solche nicht 
rom Einzelnen zum Ganzen, sondern von der Idee des' Ganzen zum Einzelnen fortschreitet". "Das Zúveckprinżip bleibt bei Kañt selbst nicht auf den Gedanken der formalen $Z$ weckmäßigkeit be= schränkt, sondern es exweitert sich zu dér Idee einues absolựtén Endzwecks, in welchem die beiden Gebiete der Natur und der Freiheit ihren letzten Zusammenhang finden sollen. Hier hât daher die immanente Entwickelung der kritischen Methodik selbst zũ einem Punkte geführt, an dem sie über sich selbst gleichsam hinauswächst" (S. 15). Wir haben uns hier gànz auf die Wieder= gabe der Cassirerschen ÄnBerangen beschränkt, nm es recht deatlich.

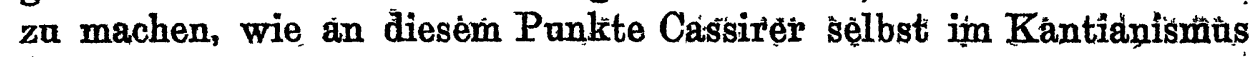
den absoluten Idealismus aufdeckt. Ein Hinwèis auf die Methodenlehre in der Kritik der reinen Vernunft und auf den gànzen Tenor der Kritik der praktischen Vernunft würde außerdem 'klarstellen; daß die in der Kritik der Urteilskraft entfälttete Anschaung nichít ein späteres Accidens za Kants ursprünglicher Pbilosophie, 'sonder von jeher das Ziel gewesen ist, dem sein gesamtes kritisches $\mathrm{Be}-$ streben gegolten hat. Die Bemerkung Arthar Lieberts, daß die kritische Methode Kants dazu bestimmt gewiesen sei, der Leibnizischen Metaphysik die methodisçhe Begründung zú liefern, dürfte demnach wohl das Richtige treffen.

Für den kritischen Idealismus in der Form, die er durch Kant erhalten hat, wird durch die Cassirersche Darstellung unser Satz erhärtet, daB er seinem Wesen nach absoluter Idealismus ist; was ihn von dem absoluten Idealismus seiner Nachtolger trennt, ist nur der Umstand, daß er in dem idealen Zusammenhange von Denken und Sein wohl das eine Moment fésthält, wonach dieser Zasammenhang eine notwendige and vernünftige Forderung des menschlichen Denkens ist, das andere aber bei Seite läßt, wonach die Möglichkeit einer solchen Forderung in nichts anderem begründet sein kann als in der Bestimmung, die sich der denkende Geist selber gibt. $\mathrm{DaB}$ also der Geist allein als der Grund zu fassen ist, der Sein and Denken als seine eigenen Momente produziert and in dem Sein and Denken deshalb identisch sind, diesen Schluß weigert sich der Kritizismas zu ziehen. Gefühlsmäßig ist es die Scheu vor einem Rïckfall in den Dogmatismas, was ihn hindert, diesen Begriff der obersten Einheit, za dem er sich geführt sieht, ernsthaft anch zum obersten Prinzip der systematischen Erkenntnis za machen; er läbt ihn als einen „Grenzbegriff", als eine Idee stehen, auf die der Verstand wohl hinanskommt, bei der er

Kantztndien, SXVIr. 
aber schon aaber sich and bei der es ihm daram nicht gehëuer ist. VerstandesmäBig ist es die abstrakte Fassung des Gegensatzes von Erfahrungsinhalt und Transzendenz, weswegen der Kritizismus, obwohl er selber tortwährend den Nachweis der Abhängigkeit der Erfahrung von überempirischen Bestimmungen führt, die Bestimmung des absoluten Geistes vermeidet und hier tatsächlich sich die Schranke des "Als ob" zieht: Wenn Cassirer mit Recht sagt, dab es nicht das Interesse der Transzendenz gewesen sei, wodurch das Denken über diese Stellungnahme vorwärts getrieben warde, so maß man zufügen, daß gerade amgekehrt der Kritizismus dies Interesse der Transzendenz gewabrt, sie als ein isoliertes and anzugängliches Abstraktum. festgehalten hat, wogegen der spekulative Idealismus ihr diesen Schein der Selbständigkeit abzustreeifen und sie als ein Moment in der Totalität der geistigen Wirklichkeit immanent zu fassen, die gesamte Diesséitigkẹit mit ihr zu versöhnen unternommen hat. Was ihn daza trieb, war in der Tat nicht das Interesse einẹs ontologischen oder gar aủßerphilosophischen, religiösen Dogmatismus, sondern um mit Cassirer zu sprechen, „das Interesse an der systemátischén Gestaltang der Er̃fahrüng selbst, das eine Erweiterang der Befugnisse- des Denkens, eine tiefere Gestältung deș Verhältnisses des Allgemeinen und Besondern fordert" (S. 16). Deshalb rühmt Cassirer den nachkantischen Lehren als eines ihrer wesentlichen geschichtlichen Verdienste nach, daß sie den Problemkreis Kants und der kritischen Philosophie erweitert haben, und meint: „Auch wenn man die neuen Antworten, die hier gegeben werden, als ungenügend und als voreilige dogmatische Entscheidangen ansieht, so wird man sieh doch den neuen und wichtigen Fragen, die hier geprägt worden sind, nieht auf die Dauer entziehen können" (S. VII).

Wir können für unsern Ziweck die Betrachtungen übergehen, die Cassirer den Kantianern Reinhold, Beek und Niaimon und den Antikantianern Jacobi and Aenesidem gewidmet hat. An den fruchtbaren Kern der Kantischen Lehre, rührt von ihnen am nächsten Maimon heran, der dem Neukantianismas besonders darum interessant sein mub, weil er zur Aufstellung der kritischen Position sich der Analogien aus der Mathematik bedient hat. Gerade deshalb aber ist es nicht zu verwandern, daß er trotz der kongenialen Erfassung des kantischen Erkenntnisproblems und trotz der Neigung, es im Sinne der Kritik der Urteilskraft zu lösen (S. 94 ff.), doch bei der Idee einer Wissenschaft ankommt, 
die von dem Wirklichen immer getrennt blejbt (S. 102-f.), und bei der Idee einer Wahrheit, die nicht beansprucht, systematisch; notwendig and allgemeingültig za sein (S. 125).. Denn das Eigentämliche der Mathematik besteht gerade darin, daB die Einheit, die in ihr maßgebend ist, die Einheit der Funktion, eine Beziehüng zwischen zwei einander an sich fremden Elementen bedentet, denen - sie als ein von aủßen anferlegtes Gesetz übergeordnet ist, and daß der Infinitesimalbegriff, mit dem die Spannung zwischen Diskontinuität und Kontinuität überwünden wèrden söll, nur zu einer unendlichen Annäherung führht, die mit.unendlichem Getrennt; bleiben gleichbedeutend ist. So beweist sichon dèr Gebrauch der mathematischen Analogien die im grunde skeptische Stellung Maimons zum Er̂kenntnisproblem; Cassirer findet ihre tiefere 'Begründang darin, daß Maimon einseitig nar die Kritik der reèinen Vernunft berücksichtigt habe und iv führung und Fortbildung, die der Grûndgedañke in Kants Ëthik and Ästhetik erfährt, so gut wie unberührt" gebliebèn sei (S. 121).

Das ist nun bei den drei großen Vertretern dès spekulativen Idealismus, bei Fichte, Schelling und Hegel vollkommenen anders. Ganz rịchtig erklärt Oassirer, daß Fichtes Philosophie auf Kants Freiheitslehre beruhe, "deren Geltang sie. schon mit der ersten Frage, die sie sich stellt, voraussetzt" (S. 131). In dem Grundakte dieser Freiheit, dem Sichselbstsetzen des vernünftigen Ich ist alles Wissen vérankert; alle Inhalte des Bewußtseins, alle Oḅjekte der Natur sind jenem SelbștbewaBtsein gegenüber sekundär. Darum aber hat die Reflexion hier verspielt, die zwischen der Materie der Erfahrung and den reinen Formverhältnissen, die sie durchdringen sollen, hin and her pendelt, ohne „die Kluft zwischen den allgemeinen Formgesetzen and der besonderen Bestimmtheit, in der sie sich uns in den Gegenständen der Erfahrung darstellen", jemals schließen zu können (S. 130 a. 134). Das peccatum originale dieser Reflexion wird freilich hier von Cassirer nicht anfgedeckt, aber in dem von Fichte zuerst rein erfaßten Begriff des vernünftigen Selbstbewaßtseins ist es überwunden: die. Reflexion reflektiert nicht anf sich selbst und wird nieht gewahr, daB sie bei all ihren Operationen schlechterdings innerhalb des Kreises ihrer eigenen Begriffe bleibt, daB es sich am lauter Probleme des begrifflichen Denkens handelt, die gar nichts mit einer jenseits des Denkens liegenden Gregebenheit zn tan haben können, sondern in dem logischen Verhalten der Selbsttätigkeit des Ich liegen; 
das Allgemeine sowohl wie das Einzelne, die Vielheit and die Einheit, ja die Materie selbst nnd die Gegebenheit - es sind alles Gedankenbestimmangen, Begriffe, nnd erst wenn das Denken sie als solche sich zam Bewaßtsein gebracht and nach all ihren Beziehangen and Zasammenhängen durchgedacht hat, ist es befugt, etwas darüber anszusagen, wds sie etwa anßerdem, daß sie seine Begriffe sind, sonst noch sein könnten. Damit stellt sich in dem Ioh, das sich selbst setzt und seines gesamten Bewaßtseinsinhaltes als seiner eigenen Bestimmungen bewaßt ist, die „vollendete Unendlichkeit “ dar, die dem Skeptizismus als ein Widerspruch erscheint (S. 131), die aber die einzige wahre Unendlichkeit ist; denn eine unvollendete Unendlichkeit ist eben Endlichkeit, bestenfalls eine aus und über sich selbst hinausweisende oder -strebende Endlichkeit. Đas Wesen der Reflexion liegt gerade darin, daß sie an diese "falsche ${ }^{4}$ Unendlichkeit gebunden ist, deren Sphäre die Welt der Erscheinungen und des Entgegensetzens von Materie and Form bildet. Es ist ganz selbstverständlich, daB sich das Denken, so lange es innerhalb dieser Sphäre sich hält, immer auf die anvollendete Únendlichkeit gewiesen sieht; in dem Angeñblick, wơ es hinter - diese Gegebenheiten auf ihren und seinen einheitlichen Grund zurückgeht, auf den Begriff des autonomen Ich, hat es. die wahre, in sich geschlossene Unendlichkeit gefunden.

NatargemäB fehlt noch viel daran, daß Fichte im einzelnen diesem. von ihm ergriffenen Prinzip gerecht werde. Cassirẹ rechnet es ihm za besonderem Lobe an, daß ihm „die Identität richt sowohl der gegebene Áusgangspunkt als vielmehr der geforderte Endpunkt der Gesamtbewegung " ist (S. 136). Dies Lob ist in dem Sinne berechtigt, daB die Identität nicht als eine "leere formale Einerleiheit" gefaßt werdèn darf :(S. 137); dem widerspricht ja ihr Begriff selbst, da zur Identität notwendig die Verschiedenheit gehört. Aber es dảrf doch nícht überšehen werden, $\mathrm{dab}$ auch die Bestimmung der Identität als einer erst herzustellenden solange abstrakt und einseitig bleibt, solange man damit die Wirklichkeit der Identität verneinen will. Die Aufgabe, die Identität herz̧ustellen, führt die. Frage nach ihrer Möglichkeit mit. sich; die Aufgabe selbt würde nicht möglich sein, wènn die Identität nicht dem Begriffé hach; als leitender Gedanke oder als Zweck etwa vorhanden und gegeben wäre. Oder man muß sagen: die ngeforderte ${ }^{\text {* }}$ Identität ist bereits auch Identitật; dàs Ich kö́nnte an ihre Herstellung nicht einmal denken, wenn es sie nicht als seine Bestimi- 
mang in sich trüge. Das Sollen setzt "Notwendigkeit für die freie Vernunft" voraus; man mag es ins Endlose formierend denken, so liegt ihm doch die einfache Wirklichkeit dés daseienden Vernanftzweckes and also eine ursprüngliche Identitiät zagrande. Für Fichte dagegén wird es verhängnisvioll, daß er den ersten Fortschritt von dem Ich, das sich selbst setzt, za dèr Mañnigfaltigkeit seiner Bestimmangen nicht rein aus dèm Begriffe des Ich heraus vollziehen kann; die Art, wie er Ich and Nichtich im Ich einander gegenüberstellt, geschieht wieder in der Form der Reflexion, und die vorstellungsmäßige Aushilfe der Redeweise von einer "Teilbarkeit" des Ich and des Nichtich ist davon diènotwendige Folge. Man darf die Absicht Fichtes, zur inneren Einheit der Vernunftanschauung za gelangen, und șeine steteten Versicherungen, daß or diese Einheit meine und ausspreche, nicht mit der Ausführựng dieșer Abșicht verwechseln, die ihm nie rọ̈llig gelangen ist. Er findet von dem Ich als dem absoluten Subjekte zu dem endlichen Ich so wenig die methódìsch tragbare Brücke wie von der sinnlichen Welt zuir intelligibeln. Sein großer Gejanke, daß im Anfange die Tat ist, setzt sich nicht zã der Totalität eines allumfassenden geistigen Organismus um, weil ihm die Reflexions: bestimmungen-des Handelns, das Sollen und seine Materie, als ursprüngliche Gegensätze dazwischen kommen. Das methodische Ergebnis ist deshalb bei ihm, daß die Freiheit nicht ist, weil sie immer nur sein soll, and damit steht er gegen sich selbst and seine tiefste Intuition in einem Widerspruch, dessen Qual er selbst. deatlich empfanden and den za überwinden er immer neue Formen. des Ausdrackes seiner Meinung gesucht hat.

Dessen ungeachtet ist es bewundernswert, -mit welcher Treffsicherheit er eine Anzahl von Grundlinien gezogen hat, die für den spekalativen Idealismus vón entscheidender Bedeatung sind. Man kann ans Cássirers Darstellung erkennen, in wie vielen Pankten Hegel einfach die Erkenntnisse Fichte's hat übernehmen dürfen. "Ohne SelbstbewaBtsein ist überhanpt kein Bewaßtsein" (S. 137); dem Formalismus der kritischen Untersuchungen gegenüber, die, weil sie sich auf die Möglichkeit des Erfahrangswissens beschränken and nur die Beziehumg zwischen BewaBtsein und Gegenstand betrachten, den Einheits- and Beharrangspunkt des Ich bis za dem Maße aus den Augen verlieren können, daß ihnen das Ich zn einem bloßen Schnittpunkte von Beziehungsrichtungen wird, hebt der spekniative Idealismus die Tatsache hervor, dâb 
die sinnliche Erfahrang nur einen einzelnen Béstandteil der Bewußtheit ansmacht, dem die geistige Selbstbestimmung übergeordnet ist. Er macht deshalb das antonome Sabjekt zum Ausgangspankt and sieht in dem Bewaßtsein eine Bestimmung des Selbstbewabtseins, darin zweifellos dem Kantischen Gedanken sich anschließend, der ${ }_{n}$ das Bewußtsein meiner selbst als die ursprüngliche Apperception" das "transzendentale BewnBtsein" nennt, auf das alles empirische Bewaßtsein sich notwendig bezieht, und der hinzufügt, dab "die bloße Vorstellung Ich" das transzendentale Bewaßtsein sei (Kr. d. r. V. 1. Aufl., S. 117). - Daß das Wissen System, nicht Aggregat sein -müsse (S. 137), daß die Wissenschaftslehre das zum Wissen von sich selbst, zur Herrschaft über sich selbst gekommene Wissen sei (S. 138), sind Sätze, die fast in denselben Worten von Hegel wiederholt worden sind. Auch die merkwürdige Wen$\bar{d} u n g, d a \hat{B}$ schließlich man die Wissenschaftslehre gạr nicht hat, sondern dab man sie ist und zu ihr geworden sein maB (S. 139), die Fichte später in der Form wiederholt, daß das Wissen in sich und durch sich ein absolutes Ende finde, in dem es wissend zu seinem absoluten Ursprung komme, dem Nichtwissen alles Besonderen (S. 176), ḱêhrt bei Hegel in der Ausführung wieder, daß das absolute Wissen zur Unmittelbarkeit wird. „Jedes besondere Wissen, jedes Wissen von Ëtwas verwirklicht", wie Cassirer den Fichte'schen" Gedanken wiedergibt, „den nuiverșellen Wissens=charakter, so daß er sich an ünd in ihm vollständig erfassen läßt (S. 141)"; mit dieser Begründung alles èinzelnen Denkens in dem allgemeinen-Begriffe der Vernunft, voñ dem jeder besondere Begriff ein Moment ist, hat Fichte den Standpunkt der bloßen Reflexion überwonden, den er z. B. in dem Satze dargestellt hat: ${ }_{n}$ Begreifen heißt ein Denken an ein anderes anknüpfen, das erstere vermittelst des letżteren denken.- Wo eine solche Vermittelung möglich ist, da ist nicht Freiheit, sondern Mechanismus" (S. 135). Daraus erkklärt sich auch, daß bei ihm ein außerordentlicher Fortschritt in der bewaßten Handhabang der dialektischen Methode zu ben̆erken ist. - Den Zusammenhang der Grundgestaltungen des Bewabtseins, wie Empfindung, Anschaưung, Einbildungskraft, Urteil sieht Fichte, wie Cassirer richtig ausfïhrt, darin, daß sie als die Phasen eines Fortschrittes von ${ }^{\circ}$ Gebundenheit zur - Freiheit auftreten. Cassirer sagt daża: „Die echte und wahrhafte-Geschichte des Geistes ist ... die Aưfweisung des notwendigen Stafenganges, der von dem ersten tatsächlichen Zustande der Gebunden- 
heit des Ich biṣ zưm höchsten Wissen vọn seiner wesentlichen Freiheit führt" (S. 156). Wer aber kọ̈nite verkennen, daß hier das Thema der Hegelschen Phänomenologie in voller Klarheit angegeben ist? Fügen wir hier noch das Wort bei: "Das Wiśsen kann sich nicht erzeugen, ohne sich schon zu haben, und es kann sich nicht für sich und als Wissen haben, ohne sich zu erzengen" and Cassirers Anmerkung: "Die Wissenschäftslehre erklärt somit in einem Schlage und aus einem Prinzip sich selbst and ihren Gegenstand; das absolute Wissen ist selbst die Selbstrollziehúng und Selbsterkenntnis des absoluten Wissens als solchen" (S. 185), so scheint es in der Tat, als habe man bei Fichte schon sämtliche Ingredienzien des spekülativen Idealisinüs bei einander.

Das ist auch in gewissem Sinne richtig, nämlich der Intention Fichte's nach. Systematisch hat er hinter dieser Intention żürück: bleiben müssen, weil ihm, wie obén schon gesàgt wंüride, die dụalistische Reflexion doch immer noch in die Quere kommt. Doch mạß man sich hüten, diese Unzulänglichkeit dem spekulativen Idealismus als solchem zur Last zu legen, der in der Fichte'schen Philosophie seinen ersten Flug unternommen hat. Auch Cassirer hat in seiner abschließenden Kritik des Fiehte'schen Systems sieh nicht an dessen Besonderheiten gehalten, sondern hat seinen Widerspruch gegén dasselbe geradezn auf seinen spekulativen Charakter im allgemeinen gegründet. Es tritt in diesem Widerspruch der prinzipielle Gegensatz des kritischen und des spekulativen Idealismas rein ans Licht. Sehen wir, ob er so nnüberwindlieh ist, wie ihn Cassirer empfindet.

Was er der Fichte'schen Philoșophie vorwirft, ist der Gebrauch, den sie von dem Begriff des Absoluten macht. Die Métaphysik Fichte's steht und fällt, wie er sagt, „mit dem Gedanken des schlechthin einheitlichen und eben deshalb schlechthin bestimmungslosen Absoluten" (S. 206). Hier wäre zur Erläuterung gleich beizafügen, daß natürlich daș Absolnte nur insoweit bestimmungslos heißen darf, als es keinerlei Bestimmung von außen unterliegt; die Inhaltsbestimmung, die Fichte dem Absoluten gibt, ist nach Cassirer die, daB es in einem Tun und Leben bestehe (S. 208): also ist es ein stetes Sichselbstbestimmen, ein „ruhiges Sein und Bestehen", das zugleich „actus purus", ein reines Sichselbstsetzen and -erfassen ist (S. 187). Mindestens der Absicht nach hat Fichte also das Absolnte bereits als den absolnten Geist begriffen, so wie er für den spekulativen Idealismus die zentrale 
Idee bildet. Wonn es aber bei Fichte noch schwierig scheint, den Weg von der absoluten Einheit zuir Vielheit zu finden, so ist damit nicht gesagt, daß dies ïberhaupt ein nngangbarer oder verbotener Weg sei. Darauf aber kommt nun Cassirers Widerspruch hinaus; was er an Fichte tadelt, ist nicht eine besondere Schwäche in seinem Verfahren, sondern das Verfahren überhaupt, aus dem Begriff einer obersten Einheit die mannigfachen Bestimmungen dieser Einheit zu deduzieren. "Nicht wie von der Erscheinung des Vielen zum Gedanken and zar Ideè des Einen, sondern wie von dem an und für sich seienden Einen zam Vielen za gelangen ist, lautet nunmehr die eigentliche spekalative Grundfrage" (S. 206). $\mathrm{Da} B$ diese .Frage iiberhaupt gestellt wird, darin sieht Cassirer die entscheidende Peripetie des kantischen Idealismus and den Pụkt, weswegen die nachkantische Spekalation überhaupt za verurteilen sei.

Man könnte demgegenüber zunächşt sịch auf die'Neigung berufen, die Cassirer für das mathematische Verfahren hat, and könnte fragen, ob für die philosophische Methode nicht erlaubt sein dürfe, was bei jeder Rechnung geboten scheint, nämlich daß man die Probe macht and den $\dot{W}$ eg, den man in der einen Richtung zurückgelegt hat, nun auch in der andern geht. Gesetzt, es gäbe in dem Erkennen einen Weg, auf dem man ausschließlich vọn dem Bedingten und Mannigfaltigen zù dem Unbedingten an ${ }^{2}$ Einen aufsteigen kọnnte, so wäre gerradezu die einzige Möglichkeit, ihn als richtig zu erweisen, die, daß man ihn auch rückwärts mache and vom Unbedingten and Einen bei dem Bedingten and Mannigfaltigen anlange. Vielleichht könnte man sich dạfïr auch auf Kant selbst berufen, der als das, wàs die Vernunft in dem ganzeñ Ưmang der Verstanḋeserkenntnisse' zustande zu bringen such́t, ausdrücklịch den Zusammenhang der Erkenntnis aus einem Prinzip bezeichnet and darünter ein "Ganzes der Erkenntnis" verstẹht; „weIches vor der bestimmten Errkenntnis der Teile vorhergeht und die Bedingungen enthält, jedem Teile seine Stelle und Verhältnis zu den übrigen a priori zu- bestimmen". Wenn er aber in dieșem Zusammenhange von den "Vernunftbegriffen" redet, die „nicht aus'der Natur geschöpft werden", und bemerkt: „vielmehr befragen wir die Natur nach [d. h. nach dem Maßstabe von] dieșen Ideen und halten unsere Erkenntnis für' mangelhaft, so lange sie denselben nicht adäquat ișt" (Kr. d. r. V., 2. Anfl, S. 673), so leuchtet vielmehr ẹin, daß er ein ausschließ̣lich induktives $\mathrm{Er}$ - , 
kennen gar nicht gelten läßt, sondern überall im Denken zugleich die Bewegang vom Allgemeinen zum Besonderen wie die vom Besonderen zum Allgemeinen erkennt. Dann aber ist vollends eine Darstellang des Erkenntnisprozesses, die das Beșop̣dere zum alleinigen Ausgangspunkte nimmt and das Allgemeine rein : als das Endergebnis des Prozesses aufweisen will, einseitig und falsçh and fordert die Ergänzung durch die entgegengesetzte Methode, die vom Allgemeinen ausgeht und aús ihm zum Besondern hinführt. Erst in der Vereinigung beider Darstellungsformen kann die Wissenschaft dem von ihr selbst festgestellten Tatbestande gerecht werden, daß niemals das Besondere ohne das Allgemeinìe, das Ünbedingte ohne das Bedingte denkbar und erkennbar ist. Der Forderang der philosophischen Systematik wird deshalb die Methode am vollkommensten entsprechen, die bei jeder Einzelerkenntnis ebenso wie bei dem Begriff des Wissens überhanpt diese lebendige Bewegang, dieses Hin und Her vom Vielen zum Eìnen, vom Apósteriorischen zum Apriorischen und umgekehrt wiederzuspiegeln versteht. Und man wird es als höchst nnerheblich-ansehen dürfen, welches von beiden Momenten dabei zuèrst herangenommen wird, da notwendig jedes von beiden ebenso als Ausgangs- wie als Endpankt der Betrachtung wird dargestellt werden müssen. Daß Kant selbst eine solche Methode vorgeschwebt und er ein vollkommen inheitliches System der philosophischen Erkenntnis zam Ziele gehabt hat, ist offenbar. Er sagt zwar, daß die Philosophie zwei Gegenstände habe, Natur und Freiheit, aber or erklärt zugleich, daß sie das Natur- und das Sittengesetz „anfangs in zwei beśonderen, zuletzt aber in einem einzigen philosophischen System" enthalte (ebd. S. 868). Dies einzige System anszuführen ist ihm nicht vergönnt gewesen; der Gedanke daran scheint ihn bis in seine spätesten Jahre verfolgt $z u$ haben. Dieser Gedanke aber setzt jedenfalls einen „Vernunftbegriff" voraus, der, nicht aus der Erfahrang geschöpft, die Einheit beider Sphären konstituiert und den Maßstab bildet, nach dem beide zusammen befragt werden

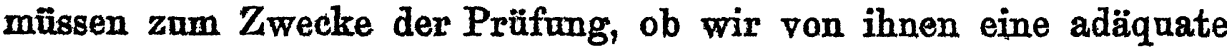
Erkenntnis haben. Damit wäre jenes Eine and Unbedingte gesetzt, das nicht als Negation des Vielen und Bedingten dieses zurückstöbt, sondern es als seine Momente und konkrete Selbstbestimmungen in sich schließt. Wohingegen der bloB historische Umstand, dab Kant durch sein Festhalten an der ursprünglichen Scheidnng von Natur und Freiheit daran gehindert worden ist, 
auf der Grundlage jener höchsten Einheit ein System der absoluten Idee za entwickeln, den Geist seiner Lehre ganz anberührt läBt.

Wir haben hier, wo rein prinzipiell das Recht des spekulativen Begriffs des Absoluten erörtert werd̉en soll, uns genauer auf Kantische Sätze einlassen müssen, weil Cassirer die Debatte einfach durch Berufung auf Kant entscheiden will. DaB er an diesem Kermpunkte der Diskussion sich auf ein Zitat aus Kant zurückzieht, ist ein interessanter Beweis dafür, wie fest der Neukantianismus, trotz aller Ưmbildungsversuche der kritischen Sätze im einzelnen, sich an die Autorität Kants klammert. Aber gerade

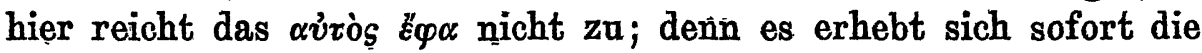
Frage nach der richtigen Interpretation Kants, und ansere obigen Hinweise dürften wohl genügen, um auch eine von der Cassirer'schen wesentlich abweichende Auffassung der Kantischen Gedanken möglich erscheinen zu lašsen. Cássirerr führt Äußerungen Kants. an, die unserem Zitat über Vernunfteinheit and Vernunftbegriffe nnmittelbar vorhergehen und erklären, daß niemals darch die transzendentalen Ideen Begriffe gewisser Gegenstände gegeben werden. Er rühnt die meîstèrhafte Prägnanz und Klarheit, mit der hier der Kritiker der reinen. Vernunft die Illusion aufdeckt, als ob "die Linien, in denen der Verstand seine Begriffe von Ob= jekten, nach Reihen von Bedingungen verknüpft, zu einem gẹwissen einheitlichen Ziele richtet, von einem Gegenstande selbst ausschössen, der außer dem Felde empirisch möglicher Erlienntnis läge" (S. 208). Die Hlasion, gegen die sich Kant wendet, ist, wie der Wortlaut seiner Sätze klar ergibt, die Meinung, es könne in der Sphäre der gegenständlichen Reflexion, die bedingte und der empipirischen Erkenntnis gegebene Gegenstände vor sich hat, żn einem unbedingten Gegenstande fortgeschritten werden. Diese Meinung wird keìn spekalativer Idealisst vertreten; keiner wird die barbarische Vorstellung hégen, das Absolute, Gott, sei nein gewisser Gegenstand“. Nan aber hat Kant selbst deutlich genug erwiesen, daß die Sphäre der gégenständlichen Reflexion es überhaupt nur mit Erscheinangen zu tun habe und diese ganze Verstandeserkenntnis in einem Systeme der Vernunft warzele, dessen Prinzip die Autonomie des Ich, des vernünftigen, denkenden und wollenden Selbstbewaß̣tseins ist. Es wäre in der Tat eine folgenschwere Fllusion, wollte man 'diese höhere, über die empirische -Erkenntnis hinübergreifende Sphäre gerade da vergessen, wo diø. 
sich kritisierende Erkenntnis unausweichlich auf sie hingeführt wird, und wollte man behaupten, weil die Reflexion im anendlichen ProgreB vom Einzelnen zum Einzelnen niemals das konkret. All= gemeine erreiche, sei dieses überhaupt unerreichbar.

Kant hat jedenfalls diese Illusion nicht geteilt; er hat: dem empirischen, endlichen Erkennen mit voller Klarheit das logische Erkennen aus der Vernunfteinheit entgegen gestellt. DaB diese Entgegenstellung selbst noch eine Folge des Gebundenseins an die endliche Reflexion ist, daß man Verstand und Vernunft so abstrakt, wie Kant es tut, nicht scheiden kann, und daif wegen dieser abstrakten Scheidung die Vernunft bei Kant zuerst in einen unhaltbaren Gegensatz gegen die Wirklichkeit zu geraten scheint, den er erst hintẹnnach durch den Begriff der ZweckmäBigkeit der in der Natur immanenten Vernanft überwindet, das wollen wir nur erwähnén, üm nicht in dèn Verdacht za kommen, als wüßten wir es nicht; dàs Eingehen darauf würde úns vom Thema za weit abführen. Nưr darauf maß hingewiiesen werden, daß sich Kant, indem er an das System der Erfahrung geht, ehe er das System der Logik ètwickelt hat, von Anfang ân in eine Schwierigkeit verstrickt hat, die nicht einmal so sebr ihm selbst wie seinen Schülern verhängnisvoll geworden isț. Während er sich der kategoriàlen Natui des Denkens vollkommen bewabt ist, bält er sich bei seiner Analyse der Erkenntnis an diejenige Form der Denktätigkeit, die durch den Gegensatz von Bewußtsein and Gegenstand schon bestimmt ist, and findet von der Vorstellang einer aus beiden gemischten Erfahrung nur mühsam and unvollkommen den Weg zu der gedanklichen Grundlage aller möglichen Frrahrang. Das tritt gerade an der Art hervor, in der er an der von Cassirer zitierten Stelle die Idee des. Absoluten behandelt. Er hat gezeigt, wie der Verstand von der Verknüpfung bedingter Gegenstände $\mathbf{z u}$ der Idee eines Unbedingten fortgetrieben wird, das entsprechend der SchluBform, mit der, and der Reihe der „Begriffe von Objekten", an denen er za ihm aufsteigt, eine bestimmte Gestalt annimmt and je nachdem als Seelenidee; Weltidee, Gottesidee bestimmt wird. Dann aber erklärt er abschliəßend es für eine Illasion, jene Idee des Absoluten für mehr als einen focus imaginarius zu halten and sie als einen Gegenstand zu betrachten. Nan ist das Merkwürdige, daB er selbst weit davon entfernt ist, Seele, Welt and Gott bloB als focos imaginarios gelten zu lassen; nur der Weg, anf dem er den Verstand za diesen Ideen gelangen 
läBt, erscheint ihm unfähig, za einer. inhaltsvolleren Bestimmung dieser "Grenzbegriffe" zu führen, womit er vollkommen recht hat. Mit diesem Wege nämlich stimmt es in keinem Pankte. Das Absolute ist ebensowenig ein Gegenstand wie ein Grenzbegriff, der, wie Cassirer sagt, erst „entsteht, indem wir den Gebrauch des Verstandes and einzelner seiner Kategorien von jeder Bedingtheit and Schranke, die ihm innerhalb eines bestimmten Gebietes der Erfahrung anhaften, befreien and ihn ins Unbedingte erweitern" (S. 207). Wenn das mehr sein soll als eine psychologische Beschreibung, dann ist es der sonderbarste circulus vitiọsus. Er setzt voraus, $\mathrm{daB}$ "wir" - gemeint ist doch das vernünftig denkende Subjekt - den Begriff des Bedingten gefaßt haben sollen ohne den Begriff des Unbedingten und daß dann in uns der Begriff des Unbedingten entstehen soll, in dem wir den des Bedingten "ins Unbedingte" erweitern. Wie könnten wir aber von einer Bedingtheit und Schranke, die unserm Verstandesgebrauch und seinen Kategorien anhaften, etwas wissen, wie könnten wir das bestimmte Gebiet der Erfahrang als die Sphäre der Bedingtheit and Endlichkeit ansehen, wenn wir nicht den Begriff des Unbedingten mit dem des Endlichen zugleich besäßen? Es ist nichts als oine Täuschung der empirischen Reflexion, wenn man sich vorstellt, durch Betrachtung bedingter Gegenstände gelange man za der Idee des Ưnbedingten; man kann keinen Gegenstand und keine Verstandesbestimmung als bedingt bezeichnen, wenn man nicht den Begriff der Bedingtheit ebenso wie der Ụnbedingtheit darauf anwendet. Das Unnbedingte und das Bedingte, das Absolute and das Relative sind Kategorien genan so gut wie die wenigen, die Kant anf seine Kategorientafel gesetzt und von denen er gemeint"hat, daß sie alle ursprünglich reinen Begriffe der Synthesis ausmachten. Dèr zufällige Ausgangspunkt, den er für ihre Aufstellung genommen hat, ist ihm zum Hindernis für ein in sich gegrüindetes umfassendes logisches System geworden. Sobald aber das Denken den Boden eines solchen Systems gewonnen hat, in dem die innere Ziusámmengehörigkeit des Einen und des Vielen, des Endlichen und des Unendlichen, der Wirklichkeit und der Vernunft, des"Aposteriori und des Apriori aus dem Zentralbegriffe der Freiheit des sich selbst bestimmenden Geistes sich ergibt, ist der Vorwarf Cassirers's ohne jede Kraft, daß die Spekulation allen sicheren Boden verliere, wenn sie, um das Absolute desto sicherer zu ergreifen, den Zusammenhang únd die Relation des Absoluten .. 
mit der Wissens- und Willenswelt abbreche (S. 209). Wie könate denn um alles in der Welt die Speknlation so närrisch sein, das za versuchen? Werin bei Fichte sich Äußerungen finden solltë̀n; die man dahin deuten müßte, dann wäre damit nur bewiesen, däB er in einseitiger Übertreibang seines Prinzips sich von seinen eigenen Grundlagen irrtümlich entfernt habe. Aber den spekalativen Idealismus als solchen, der seinen Namen gerade von dem Zusammenschaten des Mannigfaltigen und Entgegengésetzten hat, kann man mit einer solchen Anklage keineswegs belasten GewiB läßt sich die „Notwendigkeit für das Eine, sich in das Viele za zerspalten, die Notwendigkeit für Gott, zar Welt zu werden, aus seinem eigenen Grund nicht mehr begreiflich machen" (S. 210), wenn das Eine ein Ding, Gott ein alles Relative von sich aus-: schließendes höchstes Wesen ist. Aber wenn doch die kritische Philosophie, die Tätigkeit der denkenden Vêrnünft, die sich selbst kritisch durchdenkt, als den Ertrag der Prüfung des gesamten von der Vernunft vorgefundenen Bewabtseinsinhältes, als das Resultat, auf das notwendig das Denken, das sich selber denkt, geführt wird, den Begriff des sich selbst setzenden Ich, des Geistes gewinnt, der actus parus und schöpferisches Subjekt ist, dann hat dieses Eine in sich seinen eigenen Grund, aus dem sich die Notwendigkeit, die zugleich die höchste Freiheit ist, die Notwendigkeit seiner steten Systole zar Einheit and Diastole zam Universum sehr wohl begreift. Sagt man, das Denken steige von der Welt der Mannigfaltigkeit zu diesem Begriff anf, so kann man ebensogut sagen, er steige im Denken zu dieser Welt hernieder; indem die V'ernunft das höchste Prinzip als die Freiheit and die Versöhnung (Identität, Liebe) bestimmt, faßt sie es nicht als einen Grenzbegriff, was ohnehin wider den Begriff des Absoluten streitet, denn woran sollte das Absolute seine Grenze haben? - sondern als die Totalität, aus der die Deduktion zu dem Vielen herab genau denselben Weg geht wie die Induktion $z \mathfrak{a}$ dem Einen hinauf. Oder vielmehr, es sind überhaupt gar nicht zwei Wege, sondern es ist das Sichentfalten des Begriffes, ein stetes Ineinander des geistigen Lebens, das mit dem Besondern das Allgemeine und mit dem Allgemeinen das Besondere setzt, ein Urteilen, das gleichzeitig aus dem Schlusse der Vernunft hervorgeht and wieder in dem Vernunftschlusse mïndet.

Diese Anschanung der Totalität ist es, was Schellings Denkweise beherrscht. Cassirer weist sehr treffend nach, wie 
genau sich der Standpunkt Schellings an den von Kant and Fichte anschlieBt. „Die logische Grundlegang des Kritizismus erscheint als ein Moment der Vorbereitung für das kritische System der Teleologie, für die Analyse des Zweckgedankens and der Probleme des Organismus" (S. 226). Der Inhalt dẻr Kritik der Urteilskraft wird in der Anschaung beibehalten, dab die Natur ein Analogon der Freiheit darstellt; aber über das "antithetische Verhältnis" von Natur and Geist ist das Schellingsche Denken hinausgegangen, da die Natar selbst nichts anderes als eine Stufe in der Entwicklang und Selbstrealisierung des Geistes bedeuten soll " (S. 225). Nun haben wir oben schon gesehen, wie bei Kant selbst die Tendenz auf die Aufhebung jenes antithetischen Verhältnisses gerichtet ist. Und auf den Punkt, ron dem aus die Vereinigung der beiden Systeme von Gesetz und Freiheit allein möglich ist, der, bei Kant deutlich sichtbar, von Fichte als Prinžip seiner Lehre ausgesprochen worden ist, stellt sich mit BewaBtsein auch Schelling, wenn er den treibenden Gedänken der ganżen nachkantischen Fortbildung des Idealismus in den Worten aufdeckt: ${ }_{n}$ Wenn man sich an die Idee der Autonomie gehalten hätte, die Kant selbst als Prinzip seiner praktischen Philosophie aufgestellt hat, so hätte man leich't gefanden, daß diese Idee in seinem System der Punkt ist, durch welchen theoretische und praktische Philosophie zusammenhängen und dâß in ihr eigentlich schon die arsprüngliche Synthesis theoretischer und praktischer Philosophie ausgedrückt ist". So bestätigt sich für Schelling die Fichtesche Anschauung, daß, wạs wir Objekt nennen, nar das Produkt und der Reflex eines ursprünglichen Tuns' ist (S. 219), und daß zagleich die Handlung, in dér das Ich sich selbst aús absoluter Kausalität setzt and.weib, der Quell und die einzige, unmittelbar gewisse Rechtfertigung für den Gedanken des Unbedingten ist (S. 220). Die Frage, wie der Gedanke za der Wirklichkeit komme, ist müssig; denn es gibt keine andere Wirklichkeit als die, die er in sich seilbist hat und ist (S.239). Mit diesem Gedanken, den Schelling seinem System des transżendentalèn Idealismus zugrandelegt,' hat er das Prinzip des spekalativen Idealismus, der ja notwendig Identitätsphilosophie ist, so rein ausgesprochen, wie es auch Hèel nur je gekonnt hat.

Was nun Schellings eigentümliche Leistung für die Identitätsphilosophie betrifft, so brauehen wir fürr unsern Zweck nicht genauer darauf einzugehen, weil zu allem, was daran haltbar ist,, 
Hegel erst die vollendende wissenschaftliche Durcharbeitung hinzagefügt hat. "Damit wird die fas̀t unheimliche Genialität Schellings, in der eine beinahe grenzenlose Rezeptivität mit der Gabe verbunden war, alles Aufgenommene in das lebendige Ganze der großen ihn beseelenden Ansehanung einzufügen, in keiner Weise herabgesetzt. Man kann sogar eine logische Notwendigkeit darin finden, daß, wenn das Denken die Identität als den Sinn der Wirklichkeit erfassen sollte, ihm diese Identität erst als innerliche Anschaung gewiB werden mußte, ehe es diese Anschanung in kritisch Schritt vor Schritt sichẹrnder Methode zum freien Begriff ausgestaltete. DạB die Geistesknltar seiner Zeit der Schellingschen Anschaung anßerordențlich viel verdankt und daß sie fruchtbare Anregungen auch für die Folgezeit in sich enthalten hat, steht für den unparteiischen Betrachter außer Frage. Wie sehr auch seine Natarphilosophie sich , in eîn willkürliches and phantastisches Anälogiespiel verlieren " mag (S. 238), so erkènnt doch Cassirer an, daß Schelling durch seine Kritiki an den hypothetischen "Grundstoffen" ${ }^{4}$ der zeitgenössischen Physik und Chemie in der Tat anch den empirischen Fortschritt dieser Wissenschaften gefördert und darch die zentrale Stellang, die er dem elektrischen Phänomen gegeben, dem elektrodynamischen Begriff der Materie vorgearbeitet habe (S. 237). Freilich das Wichtigere ist doch, dab er anf dem Felde der Philosophie selbst den Natarbegriff vertieft hat. Die Natar, von der er handelt, ist nicht die Natar der mathematischen Náturwissenschaft, die Abstraktion eines für sich bestehenden mechanischen Zasammenhanges, der abgesondert vom Geiste, ja sogar baar des Lebens vorgestellt wird. Der ganze Ingrimm, mit dem Fichte der Natur gegenübersteht, schreibt sich ja davon her, daß er sie von diesem Gesichtspunkte ans betrachtet. Für Schelling dagegen ist die Natur das Universum, das in jedem seiner Bestandteile Leben und der Schanplatz und das Werkzeng des Geistes ist, die lebendige Natar, da Gott den Menschen schuf hinein. Die Natur hört so auf, ein isolierter Bestandteil der Wirklichkeit zu sein, and wird zu einem durchgängigen Momente der Wirklichkeit, zu dem Ansich, das ebenso dem Geiste selbst zukommt - maB man doeh auch von der Natur des Geistes sprechen - wie den Bestimmtheiten, in denen er sich und die er in sich vorfindet. Die Einheit aber von Natur and Geist stellt sich als ein Prozeb, eine stete Entwickelung ans dem Ansich zam Leben des Selbstbewaßtseins and der Freiheit 
dar. Daß Schelling diesen ProzeB nicht methodisch za entwickeln vermocht hat, daB ihm Natur and Geist zwei Pole geblieken sind, die sich nur in einem Indifferenten, in einem Absolnten einigen, bei dem gerade dem Denken der Begriff ausgeht, daß er deshalb den Weg von dem Absoluten za der Erscheinnngswelt nicht mehr findet and in einen platonisierenden Dualismus zarückfällt, um schlieBlich ebenso das Absolute wie die Erscheinungswelt als irrationale Wesenheiten anzusehen und so die Philosophie zar Romantik hinüberzuführen, der das Unvernünftige für das höchste Prinzip und für die eigentliche Wahrheit gilt, das hat in der Tat seinen Grund in dem Umstande, den Cassirer richtig hervorhebt, daß er "die Vermittelung des Begriffs verschmäht" hat (S. 283). Eben deswegen aber wäre es falsch zu sạgen, die Identitätsphilosophie oder der spekulative Idealismus vermöge die proklamierte Vernunfteinheit nicht herzustellen, wenn eben nur das Unvermögen Schellings nachgewiesen ist, sich der Methode za bedienen, auf der doch der Idealismùs als solcher beraht, der Methode der begrifflichen Entwickelung. Wenn deshalb Cạssirer apodiktisch erklärt, daß sich die Kluft zwischen Ideenwelt und Sinnenwelt im reinẹn konstraktiven Denken selbst and kraft des: selben nicht sçhließen lasse, und fortfährt: „der Panlogismus hat hier sein Ende erreicht, die absolùte Verinünft trifft auf ein schlechthin Irrationales, dab sie weder ablehnen, noch aus sich verstehen tund begründen kann" (S. 271), so begeht er eine zn schnelle Verallgemeinerang. Nicht die absolute Vernünft, sondern das Sehellingsche Nachdenken ist: auf jenes Irrationale getroffen, and es bleibt durchaus die Frage bestehen, ob eine dem Prinzip des Panlogismus getrenere Methode nicht auch diese Kluft-zu schließen vermögen würde.

He gel hat seiner Methode diese Leistung zugetrant; er hat sich nicht mit der bloßen Versicherang íhrer Fähigkeit daza begnügt, sondern hat in unendlicher Mühe sowohl die Welt der reinen Begriffe wie die Welt des konkreten Daseins aus und nach dem Prinzip dieser seíner Methode zu einem Sýstem des Begriffes, za einem Wissen des Geistes vón sich selbst - zam Sichselbsterkennen im absoluten Anderssein - za entwickeln geșuçht. Zar Beurteilung seines Werkes muß man deshalb zwei Fragen sorgfältig auseinanderhalten, erstens diè, ob sein Prinzip vor dem Forum des. methodischen Dẹkens bestehen kann, und zweitens die, wieweit er imstande gewesen ist, dies Prinzip an dem kotr- 
kreten Stoffe rein and mit vollkommenem Gelingen darchzuführen. Es liegt auf der Hand, daß, selbst wenn man die erste Frage bejaht, man bei der zweiten Frage mit Notwendigkeit zä dèn stärksten Vorbehalten sich wird gedrängt seheñ müssen. . Denn die Aufgabe, den unendlichen Stoff der.Erscheining nach allen ihrien Besonderheiten wissenschaftlich za begreifen, ist nicht nur niemals von einem einzelnen Denker, sondern anch von dem philosophischen Denken der gesamten Menschheit nicht eher zu lösen, als bis etwa der ewige Wechsel der Erscheinung zam Stillistande- würde gekommen, also dem Erkennen nichts mehr würde übrig geblieben sein. Gesetżt also, der Vorwurf, mit dem. Cassịrer, seine Darstellang Hegels schließt, bestände zarecht, daß nämlich Hegel, ;in der Geistesphilosophie das Ideelle an das Faktische, in der Natarphilosophie das Faktische an das Ideelle verloren häbè" (S. 377), so würḍe damit zunächst nur gesagt sein, daß er in der Ausführüng seines Prinzips hinter der Konzeptỉon zurüickgeblieben sei, die ihn geleitet hat; inwiefern das die Schuld der Konzieption und dẹs Prinżips ind nicht vielmehr einfach der allem Menschlichen an= haftenden Unvollkommenheit sei, darüber wäre noch gạr nichts ausgemacht.

Das Prinzip nun, in dem das Hegelsche Denken wurzelt and von dem seine Methode unzweideatig bestimmt wird, hat er nicht erst in der Auseinandersetzung mit seinen philosophischen Zeitgenossen and in dem Bestreben gefunden, die bei ihnen entdeckten Unklarbeiten oder Unzulänglichkeiten zu verbessern; es hat längst sein Bewnßtsein gestaltet, ehe er es sich selbst zum wissenschaftlichen Begriff entwickelt hat, and es hat ihm vom Beginn seines philosophischen Nachdenkens an selbst über die nächst verwandten Denker seiner Zeit eine Überlegenheit gegeben, deren er sich auch als bescheiden Lernender immer bewaßt gewesen ist. Es ist für Cassirers Darstellning schade, daB sie den Begriff, von-dem Hegels Denken ebenso getragen wird, wie es ihn offenbart, nicht zum Ausgangspankte nimmt, ja, ihn durchweg zurücktreten läßt, den Begriff des absoluten Geistes. Was Cassirer am nächsten interessiert, ist eben der Vergleich Hegels mit Kant; darum beginnt er die Betrachtang Hegels' nit einem Abschnitt über den Begriff der Synthesis bei Kant und Hegel, und es ist verständlich, $\mathrm{daB}$ er von diesem Gesichtspunkte aus wohl bis za dem Hegelschen Begriffe des Ich, der Persönlichkeit, des Subjektes gelangt, das in sich als Einzelnes die Einheit des Allgemeinen und des Besonderen 
darstellt und dadurch die Objektivität konstitaiert. Damit ist zweifellos Hegels Meinung richtig wiedergegeben; aber die Synthesis, die seinem Geiste die ursprüngliche und grundlegende ist, wird dadurch noch nicht erreicht: sie tritt erst in den Sätzen ans Licht, das Wahre sei nicht als Substanz, sondern ebenso sehr als Subjekt aufzufassen; oder die Substanz sei wesentlich Subjekt, die Bestimmung des Absoluten als Geist sei der erhabenste Begriff and der der neueren Zeit und ihrer Religion angehöre, und die Wirklichkeit des Begriffs des Absolnten, das Subjekt ist, sei die Selbstbewegung. Mit diesem Prinzip ist die Methode der Philosophie zugleich gegeben, die das Wahre nicht bloß als ein System, sondern als ein sich ans sich selbst durch die Selbstbewegung seiner Gliedër entfaltendes System betrachtet and also der subjektiven Zataten sich enthält, um den Begriff sich selbst von einer seiner Bestimmungen zur andern forttreiben zu sehen, bis er wieder, durch die Freiheit seines eigenen Selbstbewaßtseins oder durch das Bewußtsein seiner Gültigkeit bereichert, in seinen Anfang zurückkehrt.

Sehr mit Recht bemerkt Cassirer, daß in der kantischen Philosophie die Richtung auf eine solche Gestalt der Metaphysik bestanden hat, deren „Ziel in dem vollständigen Begriff von der Organisation des Geistes selbst" läg (S. 285). 'Er erkennt demgemäß auch an, daß die dialektische Methode in streng kontinuierlicher Entwicklung aus den für die gesamte nachkantische Philosophie gemeinsamen Prämissen hergeleitèt sei (S. 305). So erscheint in gleichem Maße das Prinzip wie die Methode Hegels als der Abschluß und die Vollendung des in der kantischen Lehre zam ersten Ausdrucke gekommenen Idealișmus des vernünftigen Selbstbewaßtseins, und eben wegen dieser.Grandlage seiner Philosophie, die schlechthin auf der transzendèntalen Anschauung beruht, das Absolute in die Sabjektivität verlegt und den Satz ausspricht, daB der Geist höher ist als die Natur, steht er gegen die gesamte vorkantische Philosophie auf einem Boden mit Kant. Nar möchten wir bezweifeln, ob man mit Cassirer der vorkantischen Metaphysik in Bausch and Bogen, statt bloB den kleinen Geistern des nachleibnizischen Dognáatismus, den Vorwurf machen könne, sie habe, um ihre Aufgabe zu erfüllen, ein "Wissen von den absoluten Dingen" sein müssen, die „als schlẹchthin äußere in einem transzendenten . Bezirk jenseits des Geistes bestehen"; der ontologische Gedanke, der nichts als seinsnotwendig anerkennt, als was denknotwendig ist, trennt offenbar das Sein keineswegs äußerlich von dem Geiste, 
sondern spricht nur in unbefangener Weise den Begriff eben der Identität von Denken und Sein aus, den erst die von dèm Gesichtspunkte des Kritizismus ansgehende Philosophie sich in methodischer Vermittelung zam beherrschenden Leitsatz machen konnte. DäB nichts diesen Begriff in dem BewriBtsein der Menschbeit so wirksam belebt hat wie die Gottesidee der Offenbarungsreligion, erhellt von selbst; sie ist deshalb auch der Bodeñ gewesen für die bewußte Ausprägung des Ontologismas. Zugleich hat auf diesem Boden der religiösen Kultur aúch der Begriff des ábsoluten Geistes früher als in der Philosophie seine Ausgestaltung erfahren. Von der religiösen Grundlage seines persönlîchen Bewạtseins her ist anch Hegel die Anschanung des absolnten Geistes aufgegangen; Cassirer hat ganz richtig empfunden, daß die Réligion für Hegel das Moment der Wirklichkeit ist, aus dem er seinen Begriffe des Absolnten gewinnt. Aber es ist nicht so, dẩ sich ihm die drei Kantischen Absoluta, „wie sie im Geiste der Erkenntnis, in dem der Sittlichkeit und in dem der Kunst festgestellt sind ${ }^{\prime}$, etwa hinterher eršt in das eine Absolütum der̀ Religioñ zusammenfassén (S. 290), sondern dieses steht als beherrschendes Prinzip and leitender Gedanke ihm bereits in Form dêr Intuition fešt, wèn er daran geht, die Erscheinungen der geschichtlichen Geistes-, kultur zu untersuchen, denen ja seine frühesten Studien gegolten haben.

Daß Cassirer anf diese zentrale Stellung der Religion in der. Hegelschen Gedankenwelt aufmerksam macht, ist um iso verdienstlicher, als bei der Neubelebung des Interesses für Hegel, die wir zar Zeit beobachten können, bisher das -Hauptgewicht meist auf Hegels Stellung zam Staat and zar Geschichte gelegt wird. Ihm selbst war die religiöse Idee selbst in der Staats- and Geschichtsauffassung das Bestimmende: der Staat beruht auf Religion, die Geschichte ist Theodizee. Das ist Hegels Auffassung immer gewesen und geblieben; man wird sagen dürfen, daß er sich damit von der letzten Absicht Kants keineswegs entfernt hat. Denn was Cassirer meint, daB im Unterschiede von Kant das Problem der Synthesis and der synthetischen Einheit durch Hegel von dem Boden der reinen Erkenntnis auf denjenigen des konkreten geistigen Lebens in der Totalität seiner Änsserungen versetzt wird (S. 291), das trifft doch nur za, wenn man von der ganzen Arbeit Kants ansschlieblich seine Kritik aller möglichen sinnlichen Erfahrung betrachtet. Cassirer hat aber selbst als deu wahrhaften AbschlnB. 
des Objektivitätsproblems der kritischen Philosophie die Synthese bezeichnet, die Kant in der Kritik der Urteilskraft erreicht, den Standpunkt, auf dem die Idee der Natur selbst unter dem Gesichtspankte der Freiheit, die Idee der Freiheit selbst unter dem Gesichtspunkte der Natur erscheint (S. 288). In seiner Religionslehre wie in seinen Betrachtangen über die Probleme der Weltgeschichte hat Kant, der systematisch diesen Standpunkt an dem gesamten Erfahrungsstoff za bewähren nicht mehr vermocht hat, die fruchtbarsten Ansätze zu solcher Arbeit geliefert, die es über jeden Zweifel erheben, daß er nicht gemeint war, die Synthesis in dem luftleeren Raume der abstrakten Erkenntnistheorie eingesperrt zu halten, sondern sie als konkrete Erscheinung in der Wịklichkeit aufzuweisen beabsichtigt hat. Gerade in ihren Gedanken hinsichtlich dieser so za sagen angewandten Synthesis befinden sich Kant und Hegel vielfach in vollkommener UUbereinstimmang.

Wàs Hegels Größe ansmacht, das ist das erstaunliche Gleichgewicht zwischeñ der Gabe dèr. Intuition und der Sorgfalț des̀ methodischen Denkens, zwwischen dem Interesse an dem Leben und an der' Wirklichkeit and dem rastlosen Bohren der Abstraktion nach dem geistigen Quell alles Daseins. Dieses Gleichgewicht drückt sich gleichsam symbolisch darin aus, daß er in seinen zwei grundlegenden Werken, in der Phänomenologie ûnd in der später zar Enzyklopädie ergänzten Logik, sein System von zwei ganz verschiedenen Ausgangspunkten aufbaut. Daß etwa dịe Phänomenologie als ein propädeutisches Werk gedacht gewesen wäre, ist ein noch immer viel verbreiteter Irrtum. Sie ist nur für Leser geschriebeñ, die bereits in dem Gedankenkreise der Identitätsphilosophie heimisch und in der Dialektik des Begriffs geübt sind. Auch dab sie ein frühheres Stadium seiner Philosophie darstelle als seine Logik, trifft nicht zu. Durch die vor sechs Jahren er-. folgte. Drūcklegung seines ersten Systems ist es nun urkundlich bezengt, daß die 'Phänomenologie bereits die Hegelsche Logik in: ihrer Eigenart voraussetzt. - Cassirer hat anf jene Logik von 1802 leider nicht Bezug genommen; sie ist gerade für den Neukantianer besonders interessant, da sie den érsten Teil, dem Hegel später die Überschrift "das Sein" gibt, mit dem Titel "die einfache Beziehung " bezeichnet and den beiden andern, nachher "das Wesen". und „der Begriff": benannten Teilen die Namen „das Verhältnis“ und "Proportion" gibt. Wie weit auch dieser erste Entwurf seiner Logik an genauer Durchbildung hinter dem späteren Werke zurück- 
bleiben mag, nicht blob die Methode ist dort bereits vollkommen klar und bewußt ausgearbeitet, auch alle leitenden Gesichtspunkte finden sich schon vor. Vergleicht man die Phänomenologie mit jener ersten Logik Hegels, so wird der Titel, den er anfangs fürr die Phänomenologie gewählt and erst nacb Abfassung seiner berühmten Vorrede durch ihren jetzigen ersetzt hat, erst ganż verständlich; er hatte sie die „Wissenschaft von der Erfahrung des BewuBtseins" genannt und hat also, während er in der Logik die reinen Gedankenbestimmungen entwickelt, die jeder Erfahrüng. zugrunde liegen, hier zeigen. wollen, wie sich diese Bestimmungen in der Erfahrung selbst verwirklichen. Demạ kantîschen Kritizismús haftet der ursprüungliche Mangel an, daß er mit der Frage der Erkenntnistheorie nach den Bedingangen, unter denen Errfahrung überhaupt möglich ist, gleîch vo $\vec{n}$ vorn herein die zwei zunächșt disparaten Elemente des abstrakten Denkens und des ëmpirischën Bewaßtseins zusammenwirft und deshalb gerade bewirkt, daß sie sich beständig fliehen und nie zar vollen Einheit gëlangen. Hegel ist über diesen Mangel dadurch hinweggekommen, daß eị das logische Fundament des Bewaßtseins für sich entwickelt, die Natur der reinen Wesenheiten darstellt, die über den. Untersischiẹd von. Subjektivität und Objektivität hinübergreifend, als die reinen Gedanken das Leben des Geistes and die gesamte Welt der Wirklichkeit konstituieren. Auf diesem Fundamente hat er das System der Sabjekt-Objektivität errichtet and hat darum auch über die bloße Kritik der Erfahrung hinaus die Erfahrung selbst nach ihrer wirklichen Erscheinung und nach ihrer geistigen Wahrheit darstellen können als das Zasichselbstkommen des Geistes in dem Bewuitsein des Subjekts. Diese Aufgabe hat er sich in der Phänomenologie gestellt; er will zeigen, wie dem Bewaßtsein des Subjekts. der Geist innewohnt and in der Entwickelung, die es als denkendes and wollendes Selbstbewaßtsein durchmacht, sich zar Erscheinung der geistigen Welt vollendet. Hegels Ausgangspunkt ist hier die ursprüngliche Synthese, mit der auch die kritische Philosophie beginnt, das Subjekt der sinnlichen Erfahrung. Den Ausgangspunkt der Logik könnte man dem gegenüber als die einfache These bezeichnen, die nur erst abstrakte Wảhrheit hat, die reinen Gedankenbestimmungen, durch deren Selbstbewegung die Welt der Gegensätze and das Reich der Versöhnung oder der Geist in seiner Totalität sich entfaltet. Das Hegelsche Denken hat so vor, dem Kritizismns folgenden Vorsprung. Dieser geht einseitig von der 
Synthese, d.h. im grande von der Antithese ans, für die er stets die Synthese sucht, ohne sich darüber klar zu werden, daß ohne eine vorausliegende These selbst eine Antithesis nicht möglich wäre; denn Gegensätze sind sich eben immer in irgend eirem Etwas entgegengesetzt. Hegel dagegen geht auf dies Etwas, auf den Grand zarück, der die Gegensätze möglich macht, nämlich auf den seine eigenen Bestimmungen setzenden und entfaltenden Geist. Natürlich wird es hier auch klar, daß Thesis and Synthesis identisch sind, dab diese nur die konkrete Verwirklichang jener ist, so daß Anfang und Ende der Entwickelung so zusammenfallen wie der gewollte and der erreichte $Z$ weck. Ebenso klar ist es deshalb, daß dem Kritizismus anch jener einfache Grund, die anfängliche These nicht fehlt; er hat sie in derjenigen Synthesis, die er als wirklich und ursprünglich anschaut, in dem vernünftígen Selbstbewaßtsein, dem- autonomen Ich, and gelangt sogar von da ans neuerdings bis za einem Logismas, der dem Hegelșchen außerordentlich ähnlich scheint. Aber er will es nicht wahr haben, daß er damit zu dem Einheitsprinzip vorgedrungen ist, das den Gegensatz produziert, zu der These, die sich durch die Antithesis zur Synthesis vollendet, sondern er haftet fest-an der Antithese und sieht zwar die Bewegung ihrer Vermittelung, aber nicht den unbewegten Beweger, dẹn. Geist in der bleibenden Organisation seines vernünftigen Wesens, wie er „vor der. Erschaffung der Natur und eines endlichen Geistes ist ${ }^{\star}$. Dabei aber beschäftigt er sich unablässig mit diesem ersten Prinzip; denn die reinen Gedảnkenbestimmungen sind der feste und unveränderliche Maßstab - seiner kritischen Denktätigkeit, übrigens ein Beweis dafür, daß der Begriff dẹ Sübstanz durch den der Funktion nicht „ersețzt", d. h. beseitigt, sondern vielmehr bestimmt wird. . Und so ergibt es sich hier aufs neae, daß der-kritische Idealismus an sich abso: later Idealismus ist, nür ohne selbst sich dessen bewaßt zu sein.

Damit sind wir dann noch einmal darauf gewiesen, prinzipiell den Vergleich zwischen kritischem und absolutem Idealismus zu ziehen, wie es Cassirer am Schlusse seiner sehr eingehenden Wiedergabe der Gèdankenentwickelung in Hegels Phänomenologie und Logik únternommen hat. Cassirer meint, das System Hegels habe „den geschiehtlichen Beweis für. die Unlösbarkeit der Probleme" geliefert, „mit "denèn schon Hegels Ausgangspunkt und Fragestellang die Philosophie. belastet" (S. 366). Dieser Satz klingt an sích einigermaßen überraschend; denn man müßte áús 
ihur schließen, daß es gewisse Aüsgangspunkte und Frăgestellungen gebe, deren sich die Philosophie za entschlagen habe, weil sie auf unlösbare Probleme führen. Es könnte dann immerhin àls ein geschichtliches Verdienst gelten, wenn ein Denker eịmal "solche Probleme aufgeworfen hat; aber nachdem er an ihrer Lösung gescheitert ist, scheint es der Philosophie gebühren zu sollen, dab sie von ihnen als von rebus iudicatis sich ternhalte and sie auf sich beruhen lasse. Das ist nun freilich eine Auffassung, die sich mit dem Begriffe der Philosophie ebensowenig reimt wie mit deren tatsächlichem Verhalten. Das philosophische Denken läßt sich keine Grenzpfähle stecken, and wenn es sie sich selbst steckt, só hat es damit schon die Grenze überwanden; denn es kann sie nicht ziehen, ohne diesseits und jenseits von ihr Bescheid za wissen. Und deshalb legt. die Philosophie niemals ein Problem als anlösbar beiseite; entweder sie führt den methodischen Beweis, daß es an sich unlösbar sei, und dann hat es aufgehört, ëin Problem zu sein, und seine Lösüng ist gelungen in dem Nachweise, daß nor der Schein eines Problems vorgelegen habe; oder aber das Problem wird dauernd als ein solches empfunden, und dann genügt kein geschichtlicher Hinweis auf einen mißglückten Ver: such, es za lösen, sondern der. denkende Geist mächt sich immer aufs neue daran, die Wahrheit zu begreifen, die ihm in Form des Problems entgegentritt. Cassirer hat selbst den Nachweis geführt, wie mit innerer Notwendigkeit aus dem Standpunkte des Kritizismus die Fragestellnngen der nachkantischen Philosophie sich ergeben haben. Es sind also sachlich notwendige Fragestellangen, and man kann sie nicht deshalb abweisen, weil sie die Philosophie mit Problemen belasten, die man für unlösbar erklärt, und noch weniger, weil man meint, daß Hegel seinerzeit sie nicht befriedigend beantwortet habe.

Non ist weiter die Frage, wieweit überhaupt die Vorwürfe berechtigt sind, die der Arbeit Hegels im einzelnen gemacht werden. $\mathrm{DaB}$ er die Sache nicht für alle Zeiten endgiltig ins Reine gebracht hat, versteht sich von selbst; ob aber die Mängel seiner Darstellung so grob sind and seiner Methode selbst so kraß entgegenstehen, wie man hänfig annimmt, ist doch sehr zweifelhaft. Es ist vieles von dem, was ibm zum Vorwarf gemacht wird, reines Mißverständnis. Schon Schelling hat, wie Cassirer erwähnt (S. 281), gegen Hegels Logik den seitdem immer wieder erhobenen Einspruch geltend gemacht, daß, wenn man mit dem reinen abstrakten 
Begriff des Seins anfange, man za.inhaltreicheren Bestimmangen nur durch Erschleichung und Supponierung eines Seienden gelangt, eines letzten Subjektes des dialektischen Prozesses, das sich in ihm ind durch ihn entfaltet. Cassirer selbst faßt die Dialektik bei Hegel so, daß für sie das Absolutè nicht mehr den unmittelbaren Anfang der Philosophie, sondern ihr Ende, nicht mehr ihre Voraussetzang, sondern ihr Resultat bedente (S. 303). Aber in seiner Kritik der Hegelschen Logik erklärt er selbst, daß dieses Resultat schon in jeder Phase des Prozesses, in jedem neuen Übergange als das eigentlich bestimmende und vorwärtstreibende Prinzip wirke (S. 367). So wird es wohl ein Irrtum sein, wenn man Hegels Methode dahin auslegt, er fange mit dem absolut Leeren, dem Sein an, das mit dem Nichts identisch ist, und lasse dieses sich durch Selbstbewegung bis zum Begriffe der Totalität erweitern, einem schlappen Beutel gleich, den man aufbläst, bis er platzt. Cassirer meint: „nach der Grúndvoraussetzung Hegels soll jedes einmal gesetzte Moment sich selbst negieren und durch diesen Widerspruch das Denken žtu einem andern und höhern hinaustreiben" (S. 366). Abgesehen davon, daß die Art der Eintgegensetzúng der einzelnen sich gegenseitig fordernden Gedankenbestimmungen in den verschiedenen Sphären des Logischen nicht die gleiche und also die bloße Negation bei weitem nicht für den dialektischen Prozeb im ganzen charakteristisch ist, so spricht doch Cassirer selbsst ¥on dem "gesetzten Moment". Ja, wovon ist es denn Moment, und wodurch wird es denn gesetzt? Es ist doch offenbar, daß- die Totalität und zwar die Totalität als Geist bereits vorausgegeben ist, wenn man von gẹsetżten Momenten redet. In der Tat ist für alles Philosophieren Hegels dịe ursprüngliche İdentität, die keinen mittelbảren Beweis zuläßßst (S. 302), die unbedingte Grundlage; das cogito, ergo sum, ist der Punkt des unmittelbaren Wissens, von dem es keinen Regreß zu einem ihm vorausliegenden Prinzip geben kann, and alles Beweisen in der Philosophie bedeutet nur das Aufzeigen des notwendigen systematischen Zusammenhanges, den dies Prinzip fordert und herstellt. Es gibt darum für Hegel auch keinen eigentlichen Anfang in der Philosophie; sie ist ein in sich geschlossener Kreis, mit dessen Betrachtung das denkende Subjekt an jedem beliebigen Punkte müßte anfangen können und sich nür nach $\mathrm{Z}_{\mathrm{w}}$ eckmäß̈̈igkeitsgründen für diesen oder jenen Anfang entscheiden wird. Auch der Anfang mit der Logik ist der Anfang mit einem Momente des Ganzen and insofern èbenso za!' 
fällig, wie wenn in der Phänomenologie mit dem ñatürlichen Bewaßtsein angefangen wiird. Nur weil das Logische das übergreifende Moment, sowohl eine besondere, als auch die allgemeine Weise der absoluten Idee ist (S. 363), erscheint Hegel der Anfang mit der Logik besonders zweckmäßig. Aber immer handelt es sich hier am die Darstellangs form, and dieser liegt die Idee selbst voraus. Kein Teil der Philosophie and kein einzelner Begriff der Logik kann für sich allein gedacht oder entwickelt werden; das Ganze liegt ihm zagrunde, trägt and bestimmt ihn. Das philosophische Denken ist Nachdenken; es sangt sich das Wahre, das Konkrete nicht aus den Pfoten der Abstraktion und klaubt nicht aus dem Begriffe des leerên Seins und des reinen Nichts die Fülle der göttlichen Gesichte heraus, sondern es hat den ganzen Reichtum des lebendigen Bewußtseiñs und der wissenschaftlichen Erkenntnisse vor sich, es trägt die Anschaunng der geistigen Totalität and das Bewaßtsein seiner schöpfërischen. Freihèit in sich, and es gestaltet sich auf grand dieser seiner vernünftigen Bestimmtheit seine Welt zum begriffenen System, sich selbst zum absoluten Wissen, zum focus realis des absolutẹn Geistes.

Die Art, wie Hegel Sein, Nichts und Werden dialektisch anander, ganz deutlich nicht auseinander, entwickelt, gilt gewöhnlich als das eigentliche Merkmal seiner Philosophie überhaupt. Wie man Kant auf die transzendentale Ästhetik festbindet, so sieht man in dem ersten Kapitel der Hegelschen Lugik den ganzen Hegel und schlägt vor Verwanderung über den Einfall, das leere Sein zam Frandament des Universums zu machen, die Hände über dem Kopf zasammen. Cassirer hat selbstverständlich mit diesem Verhalten nichts gemein. Er weiß, daß Hegel seine Logik nicht bloß damit anfängt, zu sagen, das leere Sein sei mit dem Nichts identisch, sondern daB diesem besonderen Satze der allgemeine vorausliegt, das Sein and das Denken sei identisch. So ișt für Hegel das Sein Gedanke, das Nichts Gedanke, das Werden Gedanke, und er bringt nicht drei disparate Dinge gewaltsam zueinander, sondern er. zeigt auf, wie diese drei Gedankenbestimmungen durch das innere Leben des sie prodnzierenden Begriffes miteinander in $\mathrm{Zu}$ sammenhang stehen. Ganz richtig sagt deshalb Cassirer: „dab Sein und Nichts identisch sind, kann gar nicht anders als vom Werden ber deatlich gemacht werden ${ }^{\alpha}$ (S. 366). Natürlich, das "Umschlagen ${ }^{\alpha}$ der einen Gedankenbestimmang in die andere ließe sich nicht anfzeigen, wenn sie nicht sämtlich dem Denken in ihrer 
besonderen Bestimmtheit bereits bekannt wären. $\mathrm{DaB}$ aber nun, wie Cassirer meint, dieser Gesichtspankt dem Prinzip der dialektischen Methode nicht entspräche (S. 367), trifft keineswegs za. Auch für die dialektische Methode ist das philosophische Denken kein Konstruieren ins Blaue hinein, and der Gedanke des Systems steht ibr fest, wenn sie die Beziehung seiner Glieder sich entfalten läßt. Ohnehin besteht diese Beziehung durehaus nicht bloB in dem „Umschlagen" eines Begriffes in den andern, wie es bei jenen ersten abstraktesten Begriffen der Fall ist; sie nimmt im Fortgange zu konkreteren Bestimmangen die Form einer immer tieferen Zusammengehörigkeit an, bis die ideale Einheit der Momente des gedanklichen Organismus erreicht ist. Das ist natürlich ohne die vorausgehende Anschaung dieses Organismus gar nicht möglich. - Darum ist es nur eine Seite der Hegelschen Methode, die Cassirer mit dem Satz ausdrückt: „Das Absolute soll wesentlich Resultat sein, also erst am Ende des Gesamtprozesses heraustreten" (S. 367). Hegel selbst zeigt béständig auf, daß ebenso das Absolute das erste Prinzip und daß der gesamte Verlauf der Entwicklung nichts als das Hervortreten der im Absoluten enthaltenen und darin-sich entfaltenden Bestimmungen sei; and es geht wirklich nicht an, dieses Moment der Betrachtung als eine Preisgabe seines dialektischen Prinzips aufzufassen. Vielmehr ist "das Prinzip des Fortschritts, das ihn durch die gesamte Reihe der untergeordneten Momente bis zur höchsten Idee hinaufführt" (S. 366), eben nur die eine Seite in seiner Darstellung der logischen Idee, und das Prinzip der Totalität, die sich die Bestimmungen der einzelnen Momente gibt, ist die andere, mindestẹns ebenso wichtige Seite. Dạ „Nacheinander der Momente" ist in der Logik natürlich eine vollkommen zeitlose Aufeinanderfolge, und insofern wird man sagen können, daß sich das Absolute in einem ewigen Nun nach der Fiulle seiner Bèstimmongen durchsichtig ist, während das denkende Subjekt im diskursiven Denken nicht alles zu gleicher Zeit präsent haben kann. Aber das bedeutet nicht, daß die begriffliche Entwickelung nichts als der "Fortgang einer blob subjektiven Reflexion" sei. Hegel behauptet ja nicht, daß die Selbstbewegung des Begriffs, za deren Darstellung der Denker natürlich Zeit braucht, eine zeitliche Bewegung sei; er will „die reinen Gedanken, den sein Wesen denkenden Geist" darstellen, von denen er sagt: „ihre Selbstbewegung ist ihr geistiges Leben". Dieses geistige Leben ist zeitlos und "wesentlich itzt". Das subjektive Denken aber, das diester 
Sèlbstbewegung nachdenkt, stellt den objektiven Gang der Sache dar, indem es sich daza erzieht, die wesentlichen Zasammenhänge jener Gedankenbestimmangen aufzufassen, wonach die eine mit innerer Notwendigkeit zu der andern führt, sich in ihr aufhebt and wiederfindet usf. Den Gegensatz daza bildet dann-die subjektive Reflexion, die ans irgendwelchem partikularen Interesse ein paar beliebige Einzelbestimmungen aufrafft und in dem Raisonnement, das sich an sie hält, über einseitige Abstraktionen nicht hinauskommt. Sorgfältiger als Hegel kainn man sich nicht bemühen, diesen Fehler za vermeiden: was an seiner Darstellung des objektiven Ganges der Sache notwendig subjektiv, Angèlegenheit des Zuschauers bleibt, ist nar das zeitliche Aufzählen; die gedankliche Sukzession der Momente sucht er reịn aus dèren eigenem Charakter zu entwickeln: Freilịch vèršteht er unter dieser Sukzession nicht einen in einer Richtung geradlinig verlaufenden Fortschritt, sondern eher das Hin- and Herwañdeln dẹr "Mütter" : n Gestaltung, Umgestaltung, des ewigen Sinnes ew'ge Unterhaltung ". Es bleibt immer merkwürdig; dab man ihm seine eignen Worte nicht glaúben will. Er beschreibt selbst das Wahre mit den Worten: es sei ein bacchantischer Taumel, an dem kein Glied nicht trunken ist, und zugleich die einfache und durchsichtige Ruhe. Und dennoch meint Cassirer, daß bei Hegel schließlich die Bewegang anf die Seite des Subjekts and die Ruhe auf die Seite des Gegenstandes falle und Denken und Sein in offenbarem Daalismus auseinandertreten (S. 368).

Die Erklärung dafür, wie Cassirer auf diesen Vorwurf gekommen ist, den eigentlich jeder Satz bei Hegel widerlegt, ist darin za finden, daß er die immanenten Geltungsunterschiede übersieht, die zwischen den verschiedenen Gebieten des denkenden Bewaßtseins bestehen. Wäs für die Sphäre der zeitlosen Beziehungen der reinen Begriffe gilt, die über die Trennung von Objektivität und Subjektivität erhoben sind, das hat nicht ohme weiteres die gleiche Geltung für die Sphären, in denen sich der Gegeasatz zwischen BewaBtsein and Gegenstand auswirkt. Als allgemeines Moment ist das Logische selbstverständlich anch in diesen Sphären wirksam und gegenwärtig; aber' als besonderes Moment steht es gleichzeitig ihnẹ beiden in eigenartiger Bestimmtheit gegenüber. Der Gedanke konstruiert von dem Logischen über die Natur zum Geiste einen dialektischen Fortschritt; aber dieser Fortschritt ist ein andrer als der in der Realität, einfach weil das Logische ja nicht 
am Anfange, nicht vor der Realität steht, sondern sie als ihr eineinheitlicher Bestimmungsgrund von Anfang bis zu Ende durchdringt. Wäbrend so jene drei Sphären in ihrer Einheit eine in sich befriedigte und - wenn man die Zeitrorstellung einmal dabei will gelten lassen - in jedem Augenblick vollendete Totalität bilden, den "seligen Gott", zeigt jede von ihnen in ihrer dialektischen Verschiedenheit sich als eine besondere Bestimmtheit des Ganzen mit einer ihr eigenen Bewegung. Unter diesem Gesichtspankt erledigt sich auch der immer wieder gegen Hegel erhobene Vorwurf wegen des Überganges von der logischen Idee zar Natur: die Idee entläßt sich frei in ihr Gegenteil. Das darf man ebensowenig für die Sprache des Mythos halten, wie wenn Fichte sagt: das Ich setzt das Nichtich, oder Schiller: es ist der Geist, der sich den Körper baut. Hegel redet hier von logischen Beziehungen der Begriffe, nicht von Dingen der Wahrnehmung. Wenn man von dem Logischen als der ersten Sphäre des Syjstems beginnt, dann erscheint die Natur als seine Entäußerung, der Geist als seine Verwirklichung. Setzt man die Natưr âls die erste Sphäre, so enthïllt sich in ihr das Logische als ihr Einheitsprinzip, die Seele dieses organischen Ganzen, und der Geist als ihr Ziel und beherrschender Zweck. Geht man von dem Geiste aus, so erfaßt sich dieser in dem Logischen nach seinem an sich seienden Wesen and in der Natur als in dem von ihm gesetzten Mittel seiner universalen Selbstdarstellung nach seinem unterschiedenen Fürsichsein. Keiner dieser drei Aspekte des Systems ist für sich allein das ganze System; jeder hat einen Schein von Abstraktion an sich, den erst-ihre spekulative Zusammenfassung beseitigt. Darum aber kann man auch nicht, wie es Cassirer tut, einfach den letzten $\mathrm{Ab}$ schnitt der Enzyklopädie, die Geschichte der Philosophie, ăls das Ende der Bewegung bezeichnen, die in der Logik anfängt (S. 368). Als zeitlos dialektischer Prozeb ist die Bewegung vom Begriff des bloßen Seins .bis. zum Begriff des sich sëlbst begreifenden Wissens wohl anzusehen; wenn aber aü den Fortschritt im subjektiven Geiste reflektiért wird, wie es Cassirer hier tut, dann handelt es sich um eine in der besonderen Sphäre der geistigen Kultur verlaufende Bewegung, und die beginnt mit dem Begriffe des natürlichen BewuBtseins, um bis zumm absoluten Wissen fortzuschreiten. So kann man auch nicht folgern, daß für Hegel das Absolute die Gestalt eines einzelnen geschichtlichen Zustandes, nämlich seiner geschichtlichen Gegenwart habe annehmen müssen. Es ist richtig, daß Hegel' 
„die jetzige Zeit anf dem Standpnnkt angelang't sieht, wo das endliche SelbstbewaBtsein mit dem absoluten sich in begrifflicher Erkenntnis eins setzt". Er bietet seinen Schülern die Befrièdigung; daß in seiner Philosophie, die ja "ihre Zeit, in Gedanken gefabt“. sein will, der Kampf zwischen den. Abstraktionen der Unendlichkeit und der Endlichkeit anfhört, der noch in der düalistischen. Reflexion seiner ùnmittelbaren Vorgänger zar schärfsten Ausprägung gekommen ist. Aber wenn er meint, daß "fürr jetzt" die Reihe der geistigen Gestaltungen geschlossen sei, bemerkt er doch gleichzeitig, daß eine neue Epoche in der Welt eingesetzt habe. So kann man ihm nicht schuld geben, daß er die Weltentwicklung mit dem Erscheinen seines Systems aufhören lasse, um so _weniger, als sich bei ihm zahlreiche Änßerungen finden; die auf weiteren Fortschritt und auf später za vollbringende Lösüngèn von "Knoten" hinweisen, an denen der Weltgeist in der Gegenwart șteht. Jèdenfalls berechtigt der Umstand, daß er dén Gesan̄tertrag der bisherigen Geistesgeschichte als die bîsher vom Weltgeist erreichțe höchste Stufe der Entwickelung ansieht, nicht za dèn Vorwurf, er hạbe "ein Einzelnes and Zufälliges zûm Absoluten erhobeñ " (S. 369); eher würde zutreffen, daß er in jedem klassischen philosophischen Systeri, weil es das zum Begriff gestaltete Selbštbewußtsein einer ganzen Zeit and damit ein ewig gültiges Moment der Totalität ist, die Weltentwickelung zur Ruhe kommen sieht. So erklärt denn freilich Hegel nicht dies oder jenes jeweilig erreichte and bestimmte Wirkliche (S. 369), sondern alles Wịkliche schlechthin für vernünftig; darin eine "Gefahr ${ }^{*}$ zu sehen, ist nur dann möglich, wenn man das Faktische and das Ideelle als zwei getrennte und nie wirklich $z \mathfrak{z}$ vereinbarende Dinge betrachtet. Aber daß diese Betrachtang richtig sei, müßte erst bewiesen werden.

Den dentlichsten Beweis dafür, daß Hegels Methode in der Ausführang notwendig scheitern maß, glaubt Cassirer in der Hegelschen Naturphilosophie erbracht za sehen. Nun ist aber das Merkwürdige, daß Hegel, wo er über den Erscheinnngskiomplex redet, den die mathematische Natarwissenschaft mit dem Namen Natur bezeichnet, äußerst vernünftige, dieser Wissenschaft durchans verständnisvoll gerecht werdende Ansichten vorträgt. Cassirer weist selbst anf Hegels Ausfiuhrungen in der Logik über eine "Mathematik der Natar" hin und erkennt an, daB für Hégels Anffassung der Prinzipienlehre der mathematisch-physikalischen Erkenntnis dort "wichtige and fruchtbare Bestimmungen" gegeben 
seien (S. 342). Aber freilich erschöpft sich für Hegel der Natarbegriff nicht in der Hypothese Natur, wie sie von der mathematischen Physik ihren Berechnungen zugrande gelegt wird. Und daraus wird man ihm wieder keinen Vorwurf machen dürfen; gibt doch Cassirer selbst za, dab bereits bei Kant sich „der Wirklichkeitsbegriff der mathematischen Naturwissenschaft als eine freilich notwendige and in ibrer Geltung nnantastbare Abstraktion" erweise (S. 288), womit dann schon ausgesprochen ist, daß über den Umfang ihrer Geltung nur die Philosophie entscheiden kann. Denn deren Anfgabe ist es ja gerade, die Abstraktionen, von denén die verschiedenen Einzelwissenschaften ausgehen müssen, weil sie eben Einzelwissenschaften sind, in dem konkreten System des sich wissenden Geistes aufzuheben. Auch ist es nicht weiter zu verwundern, daß für Hegel gerade- der Begriff, von dem die mathematische Physik grondsätzlich abstrahiert,. im Vordergrande seiner Nataranschaung steht, nämlich der Begriff des Lebens. Ein großes Lebendiges ist ihm die Natur; darin steht er mit Goethe und Schelling völlig auf dem gleichen Boden; aber ernstlicher als beide faßt er die Aufgabe an, die geistige Organisation dieses I Lebens methodisch anfzazeigen. Nun ist es gewiß sehr leicht, über Einzelheiten der Hegelschen Naturdeutang zu spotten, und es ist ohne weiteres zuzugeben, daß er nicht bloß durch die außerordentlicheMangelhaftigkeit des empirischen Stoffes, den ihm die damalige Naturforschung lieferte, sondern auch durch ein übertriebenes Bemühen, die zufälligen Einzelheiten der Erscheinung in bestimmte begriffliche Gestalt zu fassen, ánf Irrwege geführt worden ist. Damit aber ist noch durchaus nicht gesagt, weder daß die Anlage seiner Natarphilosophie im ganzen verfehlt, noch daß ihre Durch: führùng in den Hauptpunkten ein Mißgriff sei.- Man muß sich nur gegenwärtig halten, was Hegels Absicht war. Er befand sich der Schellingschen Naturphilosophie gegenüber, mit deren Grundgedanken, in der Natur eine vernünftige Organisation, ein zam Geiste hindrängendes und aus dem Geiste geborenes Leben za begreifen, er gänzlich übereinstimmte. Dagegen warf er ihr vor, daß sie anstelle dès Begriffs ein onlebendiges Schema setze and statt die Gestaltungen, der Natur in ihrer Eigenart zu erkennen, sie durch die Subsumtion unter eine Anzahl von Reflexionsbestimmungen wie Polarität, Màgnetismus, Elektrizität, Sensibilität usf. gerade ihres individuellen Gepräges beraube. Deshalb war es sein Bestreben, den Sinn und die Gliederung der versehiedenen, 
Gestaltangen der Natur in ihrer Unterschiedeńheit zu erfassen. Der Vorstellung ist solches Verfahren im Einzelnen darchaus geläufig; Löwe und Bär, Palme und Eiche unterscheiden wị, unm ganz triviale Beispiele zu geben, ohne weiteres nach rein ideellen Gesichtspankten, and wenn wir uns genauer beobachten, sô bemèrken wir auch, daß wir sehr viel weniger hochstehende Gattangen im Naturleben durch ganz klare geistige Bestimmungen von einander sondern and miteinander verbinden. Dies vorstellingsmäßige Verhalten wird von Hegel zama methodischen Verfahren erhoben und dadurch vor dem Denken gerechtfertigt, daß̣ alle Sphären des natïrlichen Daseins in ihrer individuellen Bestimmtheit als Glieder eines großen geistigen Zusammenhanges anfewiesen werden, aus dem dieselbe Vernunft herausleuchtet, die sich in den reinen Gedankenbestimmungen der Logik wie in den geschichtlichen Schöpfungen des selbstbewußten. Geistes entfaltêt. Die Wirklichkeit, das Wahre sieht Hegel nirgènds in der Abstraktion; ibm isst es stets um das Individuelle $\mathrm{zu}$ tun, in dem sich das Faktische und das Ideelle unlösbar in eins verśchmolzen zeigen. Das Einzelne ist ihm das Allgemeine, und das Sinnliche ist ihm das Geistige. Was ist denn auch an dem, was man faktisch neñnt, das Faktische, wenn nicht die Bestimmtheit, die ihm im Unterschiede von allem anderen als seine ideelle Eigenart zukommt? Wenn Hegel die Natar unter diesem Gesichtspunkte betrachtet, so kann man ihm nicht vorwerfen, dab er das Faktische an das Ideelle verloren habe. - Die Verwandtschaft übrigens seiner Natarauffassung mit der Goetheschen, die sich beide Männer mehrfach freudig bezengt haben, wird dadurch nicht verneint, daß Goethe einmal im Jahre 1812 an einem ans dem Zusammenhange gerissenen Zitat ans der Vorrede zar Phänomenologie (nicht, wie Cassirer meint, aus der Iogik), das er anf dem Titelblatte eines Buches von Troxler als Motto fand, starken AnstoB genommen hat (S. 375); ein aufklärender Brief von Seebeck hat ihn schnell beruhigt, und er hat erklärt: ${ }_{n}$ Hegel ist bei mir entsühnt" ( S. 1207).

Ohne weiteres zazugeben ist, daß die Hegelsche Natarphilosophie eine Disziplin ist, an die der Kritizismus kanm gedacht hat; in ihr erneaert sich die Betrachtungsweise Jakob Boehmes, die dem rationalistischen Drange zar Mechanisierung and Entgötterung der Natur immer ärgerlich sein wird. Deshalb ist es wohl za begreifen, daB nichts an Hegels System so kräftig per- 
horresziert wird wie seine Naturphilosophie, obwohl sie nichts anderes unternimmt, als daB sie den kritischen Gedanken, den Sinnbezug der Gegebenheiten verständlich za machen, auf das Gebiet des Naturlebens anwendet. Merkwürdiger dagegen ist es, daß sich der Kritizismus auch gegen die Geschichtsphilosophie Hegels ablehnend verhält; denn hier findet sich nicht nar bereits bei Kant selbst die prinzipielle Wegbereitung, sondern auch, was Cassirer selbst über diese Disziplin sagt, steht in voller Übereinstimmung mit den Gesichtspunkten, von denen Hegel sich-leiten läßt. Cassirer stellt der Geschichtsphilosophie die Aufgabe, „Prinzipien und Richtlinien des geistigen Lebens aufzustellen, das im übrigen seinem eigenen unendlichen Fortgang überlassen bleibt" (S. 369); worin hier ein Gegensatz gegen die Hegelsche Auffassung der geschichtlichen Wirklichkeit liegen soll, ist nicht za erkennen. Denn es kann doch nicht gemeint sein, daß die Prinzipien and Richtlinien anders woher gewonnen werden könnten als aus dem sorgfältigen Eingehen auf die Tatsachen jener Wirklichkeit.' Der faktische Verlanf und der wirkliche Inhalt des gèistigen Lebens maß genau beobachtet werden, wenn man seine Prinzipien ermitteln, Ausgangspankt und Ziel der Bewegúng muß denkend festgestellt werden, wenin man ihre Richtlinien angeben soll. Der Gedanke maB also aus der Einzelheit den allgemeinen Sinn erfaßBt, èr muß die Idee oder den Gesamtgehalt des ganzen Verlaufes "vorweggenommen" haben, wenn èr überhaupt ihn vernû́nftig be: arteilen will. So hat. es schọn Kant gehalten bei seinem Versuach zum philosophischen Verständnis der Weltgeschichte; so hält es jeder Transzendentalphilosoph, wenn er über Themen der geschichtlichen Geisteskultur handelt, und anders hat es auch Hegel nicht gemacht. Alle wollen sie die "konstitutive Regèl" finden, die das Gānze behërrscht und bildet (S. 373); natürlich ist damit auch gesagt, das Ganze sei, bereits vor seinem Ablauf oder unbeschadet seines unendlichen Verlaüfes in der Zeit, dem Denken schon vorausgegeben, and das Einzelne müsse, um, als dem Ganzen zugehörig gelten za·können, als Verkörperung der konstitutiven Regel, àls eine Gestaltang des dem Ganzen innewohnenden Begriffes sich wirklich erweisen lassen. Ebenso sind der kritische and der absolute Id̄ealismus 'darin ganz 'einig, dả sie den Inhalt des präitischen, religiösen, ästhetischen Bewußtseins nicht durch einen andern "er ${ }^{2}$ setžen" wollen; es ist nichts als ein glattes Mißverständunis, das. von Cassirer leider wiederholt wird, daß bei Hegel die Kanst und, 
die Religion ${ }_{n}$ nar in dem Sinne begründet würđen, daß sie zugleich erledigt werden and ihre autonome and selbständige Geltung verlieren, um dem eignen Systemzweck untergeordnet and eingefügt zu werden" (S. 372). Man kann die Tendenz der Hegelschen Philosophie gar nicht besser charakterisieren als mit dem, was Cassirer als die Methode der kritischen Philosophie bezeichnet: „die Fiinheit der Vernunft in ihren verschiedenen Grundrichtangen im Aufbạu and in der Gestaltung der wissenschaftlichen, der künstlerischen, der sittlichen and der religiösen Welt als solche zù erweiseñ" (S. 373); das ist geenau der Sinn des Heḡelianismus. Das beherrschende and umfassende Prinzip, das Cassirer anter dem Namen des „eignen Systemzwecks" bei Hegel ablehnt, das erkennt er hier unter dem Namen "Einheit der Vernunft" ausdrücklieh an. Die Aufgabe nun, diese Einheit zu erweisen, ist offenbar nicht anders Iösbar, als wenn gezeigt wird, daß and warum in der Vernunft jene verschiedenen Grundrichtungen begründet sind and wie sie tatsächlich zar lebendigen Einheit des sich als freie Totalität erfassenden Geistes zusammengehen. Daß̣ diese Totalität, die Einheit der Vernanft, über jedes ihrer Momente übergreift und dabei, in der Form des absoluten Wissens, selbst als abschließendes oder bekrönendes Moment erscheint, ist die eine Seite der Sache; dab Hegel sie, der systematischen Art seines Denkens gemäß, der andern Seite gegenüber, wonach jedes der Momente selbst arch die Totalität and eine Form der absolnten .Wahrheit ist, nicht vernachlässigt hat, dürfte man ihm kaum zum Tadel rechnen. Ganz im Gegensatze zu solchem. Tadel, der den Vorwurf der Vereinerleinng and Negation der Besonderheit enthält, wird Hegel gleichzeitig deswegen getadelt, daß er die Mannigfaltigkeit der Kulturformen and des Kulturbesitzes "bis in die letzten Einzelheiten " as der Vernunft habe ableiten wollen (S. 373); davon ist in Hegels Werken nichts za finden, da vielmebr Hegel das Beiherspielende und Nebensächliche sehr klar in seinem Unterschiede von dem Wesentlichen and Bedentenden erfassen lehrt. Es blieb. anderen, die durchaus nicht anf Hegels Bahnen wandeln, vorbehalten, die Allongeperücken oder die doppelte Bachführang aus dem Begriff der jeweiligen Kaltureinheit, der sie angehören, za deduzieren. Doch müssen wir das bei Cassirer unberührot gebliebene Problem des Zufalls, der vom Begriffe zwar umgrenzten, aber in sich freigelassenen Sphäre des Akzidentiellen, hier beiseite lassen, um nicht ins Uferlose zn geraten. Hegel denkt nicht daran, 
das Zufällige, das man gern das rein Faktische nennt, zu lengnen; aber er will es an den ihm gebührenden Platz im System der Vernunft stellen und es also begreifen. Dies System in seiner inneren Lebendigkeit wiederzuspiegeln, ist die Arbeit der dialektischen Methode, die deshalb die Einheit genau so stark betont wie die Verschiedenheit. Daß Hegel den methodischen Gegensatz zwischen der Form and der Materie der Erkenntnis, zwischen dem Allgemeinen und dem Besonderen, dem Empirischen und Rationalen, dem Vernünftigen und Wirklichen beseitigt habe (S. 377), trifft so wenig $\mathrm{za}$, daB vielmehr das Gegenteil richtig ist: keiner hat mit der gleichen Sorgfalt wie er diese Begriffe in ihrer eigentümlichen Bestimmtheit herauszuarbeiten gewaß̣t. Freílich aber hat er auch gewußt, daß sie in der Einheit der Vernunft, in dem Wahren und dem Wirklichen niemals getrennt vorkommen. Wenn er sie alle als Momente aufweist; die in abstrakter Isolierung genommen, nicht nur sich selbst widerlegen, sondern ihr korrelates Moment als in ihnen selbst enthalten erkennen lassen, wenn er also die Identität des Verschiedenen zeigt, so erkiärt er damit die „Trennungen des Verstandes" wohl für überwanden, aber înicht im mindesten für inichtig" (S. 377); gibt es doch, wie man immer wiederholen żu imüssen scheint, keine Identität, wo nicht Verschiedene sind. Der Widèrsprüch des Kritizismas gegen Hégel und damit gegen den absoluten Idealismus kommt immer auf denselben Punkt hinaus, daß Hegel Ernst damit gemacht hat, die Einheit dẹr Vernunft, den Begriff des autonomen Subjekts, wie sie voñ Kant zum mèthodischen Prinzip erhoben worden sind, als zureichenden Grund für das System des gesamten BewaBtseinsinhaltes zu erweisen.. Dáa er grundsätzlich, nịcht etwa in Einzzelheiten, mit ạiesem Unternehmen geschēitert sei, läßt sich, wie wir gesehen haben, an dem Bestande seiner Lehren nicht nach $\vec{w}$ eisen; was man gegen sie einwendet, ist scchließlich vielmehr die prinzipielle, prä= judizierendè Behauptung, dem menschliehen Denken sei eine derartige systematische Erkenntnis versagt. Die Frage bleibt zu erwägen, ob diesse Behauptung stichhaltig sei.

Wir sind damit zu dem letzten Punkte gekommen, den wir noçh zu erọ̈terìn haben. Es handelt sich darum, diejenigeñ Sätze zu prüfen, die der Kritizismus als sein besonderes Erkenntnisgut dem spekulativen Idealismus gegenüber festhält und durch die er sich ihm überlegen fühlt. Es wird zu untersuchen sein, wie weit diese Sätze tatsächlich den spekulativen. Idealismus widerlegen, 
oder wie weit etwa sie selbst durçh Entwickelüng der in ihnen enthaltenen Bestimmungen auf ihn als ihre èigene Konsequenz hinführen, d. h. wie weit der kritische Idealismus nicht kritisch genug ist.

Am bestimmtesten finden wir den Standpunkt des Kritizismus bei Cassirer in folgenden Worten ausgesprochen: „Die Erfahrung und das System der synthetischen Grandsätze, auf dem sie ihrer Möglichkeit nach beraht, kann nieht mehr von etwas anderem, Höheren abgeleitet and aus ihm, als einer Vernunft höherer Art, gerechtfertigt werden" (S. 371). Es wird hier also dem Denken ein höchstes Gegebenes, ein letztes Absolutes gezeigt, über dạs ihm kein Rückgang za einem übêrgeorràneten Prinzip mehr offensteht. Nan stocken wir aber sogleich; da wir nicht ef́n, sondáern zwei sehr verschiedene absolute Dâten genạnñnt sehen, erstens die Erfahrung und zweitens das System der synthetischen Grundsätze, auf dem sie beräht; and da mạn dọch kaum zwei Absolúte gleicher Zeit wird behaupten wollen, so bleibt zu fragen, woran nun das Denken als an das höchste Prinzip sich zu halten habe, an dieses System oder an jene Erfąhrüng. Solltè darauf geant: wortet werden, die beiden ließen sich eben nicht von einander trennen, man müsse sie in ihrer notwendigen Bežiehnüg, in ihrer inneren Einheit auffassen, dann ist schon erwiesen, daß tatsächlich das Höchste weder die Erfahrung noch das System von Grandsätzen, sondern vielmehr die Notwendigkeit sei, mit der sie aufeinander bezogen, die Einheit, in der sie enthalten sind. Diese Notwendigkeit und Einheit wäre dann aber gerade jene Vernunft höherer Art, von der doch, wie Cassirer meint, der Kritizismus nichts darf wissen wollen. Damit wäre dann auch die Unzulänglichkeit des Erkenntniszieles erwiesen, das ihm Cassirer zuschreibt, wenn er sagt, die einzige Notwendigkeit, die hier gesucht wird, sei die Notwendigkeit in der Erfahrung, nicht die Notwendigkeit der Erfahrung selbst. Denn wenn doch nach den Bedingungen der möglichen Erfahrung gefragt werden soll, so heißt das: was muß notwendig vorhanden sein, damit Erfahrang möglich sei? Und bei dieser Frage handelt es sich offenbar um die denknotwendige Deduktion der Erfahrang* als soleher aus den durch den denkenden Geist geforderten Voraussetzangen; die abstrakte Unterscheidung zwischen „möglich" and „notwendig", wie sie hier der Kritizist macht, hat ihre Geltung nar innerhalb der Vorstellungs: sphäre von sinnlichen Gegenständen and erweist sich, wo es sich 
um die wissenschaftliche Erörterung der Begriffe handelt, der inneren Dialektik der geistigen Wirklichkeit gegenüber anzareichend. In dem System der Gedankenbestimmangen, darch die dem Geiste die Erkenntnis möglich wird, muß der Erfahrung ihr notwendiger Platz nachgewiesen werden, es sei denn, daß man der reinen Vernunft die Autonomie, die Kant ihr vindiziert hat, wieder entziehen will. Es zeigt sich hier wieder, welch ein Hindernis für die konsequente Durchbildung der kritischen Philosophie darin liegt, daß Kant am Anfang seiner Kritik der rëinen Vernunft sich nicht anf seinen eignen, sondern auf den Standpunkt gestellt hat, den er aufzulösen beabsichtigte. Die Annahme, als ob es keine andere als sinnliche Erfahrung gebe and alle Erkenntnis durch diese Erfahrang begrenzt sei, hat er durch den Hinweis auf die Erfahrung der Freiheit des Ich and anf die Erkenntnis der reinen Vernunft von sich selber und von îhrer Begriffswelt klar widerlegt; wenn er mit großer Hartnäckigkeit die Naturerkenntnis auf das durch die Bedingungen der äuBeren Erfahrung im Felde der bloßen Erscheinung festgehaltene Wissen beschränkt, so tut er das, um den Weg zur Erkenntnis der Vernunfteinheit and des Systems der geistigen Zwecke von jeder empirischen Bindung freizphalten. Es ist ganz gegen die p̄hilosophische Intention Kants, wenn man mit Berufung auf ihn die Erkenntnis ausschlieblich in der Sphäre der sinnlichen Erfahruing sucht. Statt des Grund- und Eckisteins, anf dem sich die Philosophie der Neuzeit aufbant, des Satzes: ich denke, mithin so bin ich, stellt man den Satz auf: ich erfahre, mithin so bin ich. Aber man beachtet nicht, daß damit nưr gesagt wird: ich denke mich als Erfahrungen machend; denn die Erfahrung- ist ein im Denken erfaßtes and vor dem Denken za rechtfertigendes Phänomen. Sagt man dagegen, daß die Erfahrung nicht mehr, von etwas Höherem abgeleitet wierden könne, so erkklärt man sie für das Absolute, dem Denken als Gesetz Aufgelegte und von ihm gehorsam Anzuerkennende. „Da liegt der Fels, man muß ihn liegen lassen; zuschanden haben wir uns schon gedacht". Das aber ist dogmatischer Empirismús, nicht kritischer Idealismus.

Die sinnliche Erfahrung kann sowenig Ausgangspankt and Richtschnur für das Denken sein, daß im Gegenteil sie als solche nưr durch das Denken zur Geltung kommen kann. Ob etwàs, wovon versichert wird, es 'sei eine Erfahrung, wirklich eine Erfahrung ist, kann immer nur die Philosophie entscheiden. Vorgestellt, 
werden kann es immer als eine Erfahrung; aber darum ist es als solche noch nicht erwiesen. Deshalb kann auch nur die Philosophie den Begriff der Erfahrung, seinen Geltungsbereich unä sein Verhältnis za den andern Momenten der Erkenntnis entwickeln; oder vielmehr dieser Begriff wird selbst vor dem philosophischen Denken sich als ein Moment erweisen, das isoliert gar nicht bestehen kann, șondern im organischen Zasammenhange des begreifenden. Wissens selbst eine Durchgangsstufe bedeatet. Cassirer meint, die kantische Kritik habe keine Antwort auf die Frage, „wie die Momente, aus denen die Erkenntnis als Gạnzes besteht, in ihrer Verschmelzang den primitiven Inhalt der Erfahrung ans sich hervorgebracht haben". Denn das einzige Datüm, auf das : sich das Begreifen und Wissen stützt, sei eben die notwendige Bezogenheit dieser Momente (S: 7). Aber daß sie notwendig bezogen sind, schließt ihre notwendige Unterscheidang in sich ein; sie sind sich also für. den Gedanken ebenso "ursprünglich fremd ${ }^{\alpha}$ wie untrennbar "zusammengehörig ${ }^{\not}$, and gerade hier tŭt sich das Problem für die Philosophie auf, das der Kritizismus dadurch nicht beseitigt, daß er einfaçh die Dualität von Stoff and Form der Erkenntnis als die Bedingung des Erfahrangswissens proklamiert. Cassirer gibt freilich zu, daß auch Kants kritische Theorie ${ }_{n}$ in der transzendentalen Einheit der Apperzeption einen höchsten Einheitsbegriff besitze, anf den sich alle Elemente der Erkenntnis, die Formen der Sinnlichkeit wie die Kategorien des reinen Verstandes gleichmäßig beziehen" (S. 371), meint aber, daß von diesem, wie Kant sagt, höchsten Pankte, an den sich die Transzendentalphilosophie anknüpfen läßt, niemals die Vielheit der Formen deduktiv hergeleitet werde. Wieweit Kant das begrifflich and methodisch für ungangbar gehalten, wieweit nur er es nicht mehr auszuführen vermocht hat, darüber brauchen wir hier nicht zu reden; im Vorigen ist ja die Sprache schon darauf gekommen. Wenn aber Cassirer in einer Weise, die als Modifikation der alten Anlagentheorie erscheint, eine oberste Einheitsfunktion der Vernunft mit der Begrïndang ablehnt, daß sich „die Einheit der Apperzeption als ein Ineinander verschiedener Erkenntnisfanktionen darstellt, von denen keine die erste und keine die letzte ist, weil sie sich alle korrelativ durchdringen" (S. 371), so wäre daran za erinnern, dab er gerade nur die eine Funktion übersehen hat, die er and alles philosophische Denken beständig iubt, die Funktion nämlich, mit der jenes gegenseitige Sichdurchdringen dar verschiedenen Erkenntnisfunktionen erkannt wird. Diese 
wird man doch wohl als die umfassende und alle übrigen bestimmende ansehen müssen.

So wenig also die Erfahrung selbst für den absoluten Ausgangspunkt der Philosophie wird gelten können, so wenig auch das System der synthetischen Grandsätze, auf denen sie ihrer Möglichkeit nach beraht; denn über beiden muß notwendig eine sie begrïndende höhere Einheit gedacht werden. Zwar meint Cassirer: „die Einheit der wissenschaftlichen Erfahrung ist das Ganze, das aus seinen Teilen nicht aufgebaut za werden braucht", das nu- $^{\text {zu- }}$ nächst nur als faktische Einheit, als das Faktum der Wissenschaft gegeben" sei, und spricht von ihm als "dieser reinen Mannigfaltigkeit der Grundformen der Erkenntnis, die nur als einfache Tatsächlichkeit aufgewiesen werden kann" (S. 370). Aber es scheint doch zweifelhaft, ob diese Vorstellangen vor der nüchternen Betrachtung der Wirklichkeit, geschweige vor dem kritischen Begriffe bestehen können. Das Faktum der Wissenschaft, ist weder als ein Gánzes, noch als ein Einheitliches gegeben, sondern als eine schier unü̈bersehbare Menge der disparatesten Wissenschaften. Thre Verschiedenheit ist so groß, daß man für die zunächst rein empirisch aufgenommenen Gattungen der Wissenschaft sogar verschiedene Logiken konstruiert, die Logik der Naturwissenschaft von der Logik der Historie unterscheidet, wobei dann drittens noch eine Logik der sìch selbst erkennenden Vernunft übrig bleibt. Dab also eine Mannigfaltigkeit der Grundformen der Erkenntnis tatsächlich anfgewiesen werden kann, würde danach zatreffen; mit

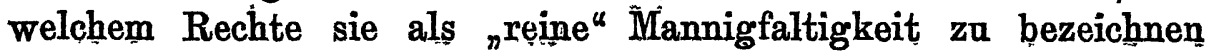
wäre und woher sie als ein Ganzes zu gelten hätte, bleibt aber völlig dunkel, solange man nụr auf das Faktum der Wissenschaft reflektiert. Die einzige Einheit, die sich da feststellen läßt, ist das Prinzip einer Beziehung zwischen Béwaßtseein and Gegënstand; aber dies Prinzip kann man nicht das Ganze der Wissenschaft oder der Erkenntnis oder der Erfahrang nennen. Die Synthese, die der Wirklichkeit wie dem Gedanken den Charakter der Totalität, der konkreten Eịnheit gibt, kann niemals in einem bloßen Prinżip; einem abstrakten Gesetz, einer formalen Beziehung, sondern nur in dem sch̆öpfẹrischen Subjekte gêfunden werden, das sich selbst und sein Anderes zugleich setzt, trennt and eint; der Kritizismus mag sich dagegen sträuben, aber er kann es nicht widerlegen,- daß von seinen Prämissen aus der Fortschritt notwendig zu dem -absoluten Idealismas führt. 
Fragt man sich, weshalb der Kritizismus sich gegen diese Konsequenz sträubt, so bleibt die einzige Erklärnng dafür diè, daß sich das Denken von der in ihm selbst empirisch vorgefundenen Trennung zwischen Bewaßtsein und Gegenstand nicht loșmaçht. Es findet zwar in sich auch die Identität und kann es nicht leugnen; daß der Gedanke selbst die Einheit von Sein and Denken ist; aber es kann sich zu dem Wagnis nicht entschließen, seiner eigènen Freịheit and Souveränität sich za bedienen und sich von jeder andern Bestimmtheit freizahalten, als die es sich selbst gibt. Unddabei ist doch dieses Wagnis in jedem kritischen Akte der reinen Vernunft schon enthalten. - Weil àber das Denken auf die ihm vertraute Dualität nicht verżichten will, so gelangt es auch, wo es die Einheitsfunktion bestimmen möchte, immer nür bìs zu Bestimmnngen, die den unversöhnten Dualismus noch in sich tragèn wie Beziehung, Gesetz, Prinzip, Bedingung, Regel, -Grrundsatz, wo ganz deatlich eine Polarität zwwischen dem Allgemeinen und dem Einzelnen festgehalten wird, die beide zu unwirklichen Abstrak tionen macht. Insbesondere ist es die-Meinung, daß die Vernunft, weil sie der Inbegriff des Allgemeingiltigen und Notwendigen ist, im Aufstellen von Gesetzen und im Aüzeigen 'gesetzlicher Zasammenhänge sich erschöpfe. Selbst die Hegelsche Auffassung meint Cassirer so ausdrücken zu können, daß ihm das Objekt als der Ausdruck und die Zusammenfassung von Gesetzen gelte, die das Wesen des Geistes selbst and seiner Funktionen ausmache (S. 288). Aber man muißte das Wort "Gesetz" schon in so erweitertem Sinne brauchen, dab von seiner eigentiimlichen Bedeutung nichts mehr übrig bleibt, wenn man die Vernunft and Wirk= lichkeit, wie der absolate Idealismus sie versteht, als ein gesetzmäBiges Kompositum annehmen wollte. Der Dichter darf, wenn ex anf die geprägte Form hinweist, die lebend sich entwickelt, von dem „Gesetze" sprechen, "wonaich du angetreten". Der methodische Denker wird hinzafügen, daß dies Gesetz vielmehr als die Idee bezeichnet werden müsse, die das innere Leben des Individuums ausmacht, während unter dem Ausdrucke Gesetz ein gegen das Individuelle gleichgiltiges Allgemeines verstanden werden maß. Deshalb verschwindet die Vorstellnng des Gesetzes, die für die mathematische Physik in der Tat alles bedeatet, bereits bei der Anschanung des Organismus, und macht dem immanenten Zwecke, der Seele, dem Begriffe der Einheit von Form und Inhalt Platz. Goethe hat diese höhere Notwendigkeit, der es übrigens sehr gleich- 
giltig sein kann, ob man sie logisch oder metaphysisch nennt, rein erfaßt, wenn er sagt: " was ist das Allgemeine? - der einzelne Fall. ${ }^{*}$ Und erst wenn die Vernunft als das Vermögen erkannt ist, die Notwendigkeit des Begriffs, die Lebendigkeit der Idee, nicht aber nur die Notwendigkeit der gesetzlichen Beziehung und das Schema der regulativen Prinzipien zu entwickeln, ist der Standpunkt der reinen, von jeder Fremdherrschaft befreiten Vernunft erreicht.

$\mathrm{DaB}$ der Kritizismus gerade in seinen modernen Gestaltangen diesem Ziele sich fortschreitend nähert, wer wollte das verkennen? Immerhin zieht er sich noch immer selbst die Schranke mit seiner Hypothese eines ursprünglich der Vernunft entgegenstehenden and $\mathrm{ihr}$ bei aller Annäherung doch zuletzt immer fremdbleibenden Momentes, einer "Materie der Erkenntnis" oder eines „Materials, das die Erkenntinis vor sich hat" (S. 365), von dem er zwar zugibt, daß es "sich durch die Formen der Erkenntnis als begreiflich erweist", aber zugleich behauptet, daß es "wenn es in diesen Formen faBbar ist, doch niemals vollständig aus ihnen abgeleitet werden kann" (S. 365). Diese Behauptung wird man getrost als reinen Dogmatismus bezeichnen können, dessen Härte nur dadurch gemildert wird, daß der ganze Gegensatz von Materie and Formen der Erkenntnis rein fiktiv ist, weil die Materie selbst in jedem Falle bereits ein Begriff, d. h. eine Form der Erkenntnis ist. Wie oft hat man sich gegen die Ungerechtigkeit des Vorwurfs erregt verwahrt, den Hegel der Erkenntnistheorie macht, daß sie die Er- kenntnis als ein Operieren mit Instrumenten ansehe, mit deren Hilfe das Denken sich des gegen sie ursprünglich indifferentèn Gegeñstandes bemächtigen wolle. Und wird dieser Vorwurf nicht durch solche abstrakte Unterscheidung zwischen einer Materie der Erkenntnis and den Formen, die sie wohl begreiflich, aber niemals vollständig in ihrer Notwendigkeit erkennbar machen können, direkt bestätigt? Gewiß, der Kritizismus hütet sich heate, von dem Ding an sich, oder gar von den Dingen an sich zu sprechen, und hat das hypothetische Etwas, das er außer dem Geiste, von dem offenbar alle "Formen" der Sinnlichkeit herstammen, noch behaupten za müssen glaubt, auf den Begriff der Unbestimmtheit selbst reduziert. Aber eben diesen Begriff will er der bestimmenden Macht des Begriffs entzogen und als ein Unnahbares und Absolutes festgehalten wissen; es ist von selbst klar, daß von dieser Grundvorausšetzung aus er jedes System der Identität von vornherein als durch den unaufhebbaren Daalismus zwischen Form und Materie 
zur Unfrachtbarkeit verurteilt ansehen maß. Aber aer Fehler liegt in dieser Grundvoraussetzung; denn vielmehr wird das Unternehmen, mit allem Scharfsinn des vernünftĭgen Denkens die Rationalität des Daseins eines schlechthin Irrationalen erweisen, also im selben Atemzuge behampten zu wollen, das Irrationale sei rational und es sei doch nichts als schlechthin irrational, immer unfruchtbar bleiben müssen. Solch ein metaphysisches Irrationales paßt in den konsequent durchgeführten kritischen Idealismus nicht hinein.

GewiB, der Kritizismas stellt das Irrationale nur als den unbestimmten Anfang an die unterste Stelle des geistigen Lebens and kommt dem absoluten Idealismus ganz nahe in der Vorstelinng einer Idealisierung des Realen, die mit der Realisierung des Idealen identisch ist. Aber indem or dem Realen eine Basis gibt, die das Geistige, Ideale schlechthin ausschließt, hält er nicht bloß dem naturalistischen Empirismus eine Hintertür offen, der sich auf dem Boden der Naturwissenschaft für unangreifbar hält unḍ sich gegen die andern Wissenschaften souverän gebärdet, sondern er fordert auch förmlich daza auf, im System des Idealismas das Irrationale zn stärkerer Geltang zu bringen. Denn schließ̉lich liegt es in dem Wesen der Idee selbst, daB sie da, wo sie angefangen hát, auch wieder endet; and so stellt sich das Irrationale notgedrangen da wieder ein, wo der Kritizismus die Summe seiner Arbeit zieht and das Verhältnis der Bezugssysteme feststellt, die or entfaltet hat. Da ergibt sich denn, daß jenseits der an die sinnliche Erfahrung geknüpften Urিteile sich Gebiete von geistigen Inhalten befinden, über deren Wirklichkeit und Wahrheit das methodisehe Denken nichts entscheiden kann; sie bleiben gerade daram irrational, weil ihnen der Ansatz einer irrationalen Materie fehlt, an den der Kritizismus alle Erkenntnisfunktionen gebunden hält. Die Sphären also, in denen der Geist wesentlich bei sich selber und in seiner Freiheit ist, vor allem die Sphäre des Glaubens und der Religion, bleiben, anch wenn sie formell logisch sich systematisieren lassen, doch nach ihrem Grunde and Gehalte dem vernünftigen Denken anzugänglich und stehen als selbständige Sphären neben ihm. Dieser Standpunkt empfahl sich den Kindern des nun zn Ende gehenden Zeitalters, weil er ihnen erlanbte, sich gegen die höchsten Lebensfragen indifferent $z \mathbf{u}$ stellen, jedem einzelnen $\mathbf{z a}$ überlassen, was er etwa von den überirdischen Realitäten denken mochte, und sich ein gates Gewrissen zo machen, wenn sie sich möglichst außer Be- 
rührang mit dem Gottesgedanken und dem Leben der Frömmigkeit hielten. Heute bietet er denen eine bequeme Handhabe, die positiv sich dem Irrationalen als dem Übervernünftigen zuwenden und unter Verachtung von Vernunft und Wissenschaft in die Bahnen Swedenborgs and Cagliostros, in die Praxis der Yoga oder der exercitia spiritnalia wieder einlenken. In philosophischer Methodik nimmt diese Bewegung die Form an, daß sie die Rückkehr hinter Kant za Plato, die Abkehr vom Denken zum Erlebnis fordert. Das Gefühl der Unbefriedigtheit, das die Menschen aùs der Freiheit der Gedanken in solche vorstellungsmäßige Unklarheit zarückfallen läßt, vermag der Kritizismus als solcher nicht zu bannen; denn er erhebt gerade die Unmöglichkeit der Befriedigung zum Prinzip. Aber in ihm selbst lebt der Drang des Gedankens, der nicht rückwärts, sondern vorwärts weist. Der Weg; den er öffnet, führt nicht hinter Kant und den kritischen Idealismus zurück, sondern mit ihm and über ihn hinaus vorwärts zu dem absoluten Idealismus der reinen und darum ebenso kritischen wie spekulativen Vernünft. In ihm erschliebt sich dem methodisch denkenden Geiste sein Urquell and seine Heimat, in ihm ist er zur Freiheit and zum Genusse seiner selbst gelangt, in ihm erfaßt er sich selbst als das begriffene and das begreifende Universum. 